\title{
Shallow plumbing systems inferred from spatial analysis of pockmark
} arrays

Ana Maia ${ }^{1}$, Joseph Cartwright ${ }^{2}$, and Espen Andersen ${ }^{3}$

${ }^{1}$ Corresponding author: 3D Seismic Lab - School of Earth and Ocean Sciences, Cardiff University, Park Place, Cardiff CF10 2FQ, United Kingdom; MaiaAR@cardiff.ac.uk

2Department of Earth Sciences, University of Oxford, United Kingdom; joec@earth.ox.ac.uk

3Statoil ASA, Norway

\begin{abstract}
This study describes and analyses an extraordinary array of pockmarks at the modern seabed of the Lower Congo Basin (offshore Angola), in order to understand the fluid migration routes and shallow plumbing system of the area. The 3D seismic visualization of feeding conduits (pipes) allowed the identification of the source interval for the fluids expelled during pockmark formation. Spatial statistics are used to show the relationship between the underlying (polarised) polygonal fault (PPFs) patterns and seabed pockmarks distributions. Our results show PPFs control the linear arrangement of pockmarks and feeder pipes along fault strike, but faults do not act as conduits. Spatial statistics also revealed pockmark occurrence is not considered to be random, especially at short distances to nearest neighbours $(<200 m)$ where anti-clustering distributions suggest the presence of an exclusion zone around each pockmark in which no other pockmark will form. The results of this study are relevant for the understanding of shallow fluid plumbing systems in offshore settings, with implications on our current knowledge of overall fluid flow systems in hydrocarbon-rich continental margins.
\end{abstract}


Keywords: pockmark distributions; spatial statistics; shallow plumbing systems; Lower Congo Basin.

\section{Introduction}

Pockmarks are evidence of highly focused fluid flow, and constitute one of the best-documented expressions of seabed fluid escape, occurring at a wide variety of marine environments (Judd and Hovland, 2007). They are shallow depressions on the seafloor, generally circular to elliptical in shape, with a diameter ranging from a few metres to hundreds of metres. Pockmarks are most commonly developed in soft, fine-grained sediments, which are remobilized or eroded by the expulsion of fluids of variable composition such as biogenic or thermogenic gas (methane), pore water, fresh water, and even oil (Berndt, 2005; Gay et al., 2006b; Judd and Hovland, 2007).

The latest advances in submarine imaging technology have led to the discovery of numerous pockmark arrays, particularly in the Holocene (Andresen and Huuse, 2011; Gay et al., 2007; Gay et al., 2006b; Hovland and Judd, 1988). The vast majority of pockmark studies describe a wide range of spatial distributions, from single isolated craters to large pockmark fields (Andresen and Huuse, 2011; Gay et al., 2006b; Judd and Hovland, 2007; Moss and Cartwright, 2010), reflecting the influence of underlying seal bypass systems. Pilcher and Argent (2007) and Gay (2007) have presented descriptions of linear pockmark alignments related to structural features such as normal faults, suggesting that fluid migration through these discontinuities is favoured over a more pervasive flow through the sedimentary matrix. Gay (2006a) and Davies (2003) interpret channel sand bodies as the shallow reservoirs supplying fluids to produce curvilinear pockmark trails. However, very few 
previous studies have explicitly identified the source layer(s) for the fluids involved during pockmark formation.

An extraordinary array of pockmarks is described here, formed at the modern seabed, offshore Angola, and based on a high-resolution 3D seismic survey. Two distinctive pockmark populations are compared and contrasted: one which is characterised by a semi-regular distribution, and one which shows pronounced alignments of pockmarks. By comparing these two sets and the feeder pipes that underlie some of the individual pockmarks, it is possible to describe in detail the shallow plumbing system of the studied area. We show that the linear alignments are entirely due to shallow normal faults. However, in contrast with previous studies, we further demonstrate that preferential alignment of pockmarks along fault strike is not due to flow focusing on the fault surface or the action of fault planes as conduits, but it is due to fault control of the position of feeder pipes that act as conduits for focused fluid escape during pockmark formation.

The main aim of this study is to explore the insights that pockmark distributions can bring on the question of source, timing, triggers, origin of fluids, and fluid migration routes, in order to improve our understanding of shallow plumbing systems in sedimentary basins.

\section{Data and methods}

The dataset for this study comprises a 3D seismic reflection survey from offshore Angola, covering an area of approximately $1600 \mathrm{~km}^{2}$ in water depths ranging from 1425m (1900ms TWT) to $2440 \mathrm{~m}$ (3250ms TWT). Bin spacing is $12.5 \mathrm{~m}$ in both inline and crossline directions. The near stack volume used to study the subsurface displays an increase in acoustic impedance (hard reflection; black) as negative amplitude, 
whereas positive amplitudes characterise a decrease in acoustic impedance (soft reflections; grey). Seafloor depth conversions are computed using a seismic velocity of $1500 m / s$ for seawater. For the Pliocene-Holocene succession, a dominant frequency of $40-50 \mathrm{~Hz}$ yields a vertical resolution $(\lambda / 4)$ of $8.5-10.5 \mathrm{~m}$, assuming an average seismic velocity of $168 \mathrm{om} / \mathrm{s}$ for the shallow sediments (Bolli et al., 1978). The horizontal resolution is $25 \mathrm{~m}$ ( $2 \mathrm{x}$ bin spacing). Well data were not available from the study area. The lithologic and chronostratigraphic framework of the region was based on information provided by ODP Leg 175 sites 1075-1077 (Pufahl et al., 1998), and by published works on the stratigraphy of the Lower Congo Basin (Andresen and Huuse, 2011; Anka et al., 2013; Gay et al., 2007; Hempton et al., 1990).

To simplify the workflow, the study area was sub-divided into mini-basins 1 and 2 (MB1 and MB2), delimited by salt-related structures. The results and interpretations presented here are based on structure maps and seismic attribute maps (coherency, dip and amplitude) produced for key horizons, complemented with vertical seismic sections along areas of interest. Each horizon attribute map was examined in detail to detect pockmarks and potential fluid flow anomalies, and investigate their relationship to surrounding structures. ArcGIS 10.1 software was used to acquire locations and morphological measurements of pipes and pockmarks, map faults, and to compute spatial statistical analysis of pipe and pockmark distributions. The spatial statistical significance of these distributions was analysed using the following univariate spatial autocorrelation statistical methods: 1) Average Nearest Neighbour $(R n), 2)$ Anselin Local Moran's I cluster and outlier analysis $\left(I_{i}\right)$, 3) Ripley’s K Multi-distance Spatial Cluster Analysis ( $L d)$, and 4) Density.

The Average Nearest Neighbour (Rn) measures the ratio of the observed average distance between each feature centroid and its nearest neighbour's centroid 
location $\left(\bar{D}_{O b s}\right)$ to the expected average distance based on a hypothetical random distribution with the same number of features covering the same total area. The Average Nearest Neighbour ratio $(R n)$ is given as:

$$
R n=\frac{\bar{D}_{O b s}}{0.5 \sqrt{\frac{a}{n}}}
$$

where $\bar{D}_{O b s}$ is the mean observed nearest neighbour distance, $n$ is the number of pipes or pockmarks, and $a$ is the areal extent of pipe or pockmark coverage in the study area.

If the average nearest neighbour ratio is less than 1 , the distribution exhibits clustering (the nearer to $\mathrm{o}$, the more clustered the distribution). If the ratio is greater than 1, the pattern trends towards dispersion. A random distribution yields a ratio of 1. To reject the null hypothesis that there is no pattern of pipe or pockmark distribution, the $Z$ score is calculated. The $Z$ score is a test of statistical significance that evaluates the standard deviation away from the mean for a normal distribution of the nearest neighbour distances $(R n)$ :

$$
\begin{gathered}
Z=\frac{\bar{D}_{\text {Obs }}-0.5 \sqrt{\frac{a}{n}}}{S E} \\
S E=\frac{0.26136}{\sqrt{n^{2} / A}}
\end{gathered}
$$

$S E$ is the standard error, and $A$ is the areal extent of pipe or pockmark coverage in the study area. Very high or very low $Z$ scores are found in the tails of the normal distribution, which indicates it is very unlikely that the observed spatial pattern is there by chance. 
The Anselin Local Moran's I cluster and outlier analysis $\left(I_{i}\right)$ uses a set of weighted data points to identify spatial clusters of points with attribute values similar in magnitude, and to detect spatial outliers. It is used in this work to measure the spatial autocorrelation of pipe source intervals, i.e. whether pipes of a particular source are preferentially surrounded by pipes sourced either from the same or from a different interval. The Local Moran's I (Ii) statistic of spatial association is given as:

$$
I i=\frac{n \sum_{i} \sum_{j} w_{i j}\left(x_{i}-\bar{x}\right)\left(x_{j}-\bar{x}\right)}{\sum_{i} \sum_{j} w_{i j} \sum_{i}\left(x_{i}-\bar{x}\right)^{2}}
$$

where $n$ is the number of pipes indexed by $i$ and $j, x$ is the variable of interest or pipe source, $\bar{x}$ is the mean of $x$, and $w_{i j}$ is a matrix of spatial weights. Pipes that are considered statistically significant outliers (pipes that have a statistically significant different source value from their neighbours) and clusters (pipes surrounded by others with a statistically similar source) have a local Moran's I (Ii) $Z$ scores <-2 or $>2$, respectively. Pipes that are not statistically significant (i.e., that there is no spatial clustering of pipe source at the 95\% confidence level) hold Ii $Z$ scores between -1 and 1.

\section{The Multi-Distance Spatial Cluster Analysis based on Ripley's K-}

function is a second order statistic that evaluates the spatial dependence (clustering or dispersion) of point data over a range of distances. The $\mathrm{K}$ function includes all neighbour points occurring within a given distance, rather than the distance to each point's single nearest neighbour. The analysis presented here implemented a transformation of the K-function referred to as $L(d)$ :

$$
L(d)=\sqrt{\frac{A \sum_{i=1}^{n} \sum_{j=1, j \neq i}^{n} k_{i, j}}{\pi n(n-1)}}
$$


where $d$ is the distance, $n$ is equal to the number of features, $A$ represents the total area of the features and $k_{i, j}$ is a weight (either 1 if the neighbouring point is within the distance of the target point, or $\mathrm{o}$ if it is not). The $L(d)$ method states that, given a random distribution of points, the expected value for any distance is the distance (d) itself (Mitchell, 2005). At any given distance, if the observed $L(d)$ values are above the expected values, the distribution is more clustered than expected for a random distribution. Lower and upper confidence envelopes for a random distribution are generated to indicate a statistically significant clustered pattern at any given distance.

PAST 3.06 software (Hammer et al., 2001) was used to detect pockmark alignments, and to perform directional statistics for one (Rayleigh's test for uniform distribution) and two samples (Watson-Williams (equal mean) and Mardia-WatsonWheeler (equal distribution) tests). PAST detects linear point alignments using the "continuous sector" method developed by Hammer (2009), and tests their significance using the Rayleigh test for circular-uniform distribution.

\section{Geological setting}

\subsection{General setting}

The Lower Congo basin is located in the West African passive margin. The basin was developed as part of breakup and spreading associated with the opening of the South Atlantic Ocean. Rifting began in the Early Cretaceous, being followed by a drift phase during the Aptian (Hempton et al., 1990). The post-rift sedimentation and structure are controlled by gravity-driven deformation above a thick Aptian evaporite décollement layer (Broucke et al., 2004; Fort et al., 2004; Lundin, 1992; Spathopoulos, 1996). As a result, the basin exhibits a thin-skinned architecture, with 
upslope extension and downslope compression (fig. 1). The study area is located in the transition zone between these domains - the diapir domain- and it is characterised by salt walls or ridges of compressional geometry (Broucke et al., 2004), which define several NNE-oriented salt withdrawal mini-basins in the study area (fig. 2).

Post-rift marine stratigraphy comprises two major sequences above the Aptian Loeme Salt layer, separated by an Oligocene unconformity, which reflects a change in ocean circulation and climate. A carbonate-siliciclastic ramp aggraded during the Late Cretaceous to Early Oligocene in response to a stable hot climate with low-amplitude/high-frequency seal level changes (greenhouse period) (Rouby et al., 2003; Séranne, 1999). Within this interval, the deep marine mudstones and black shales of Upper Cretaceous and Paleogene ages (Iabe and Landana formations, respectively) are thermogenic oil and gas generating source rocks (Cole et al., 2000).

The onset of the Antarctic glaciations and consequent global sea level fall produced the Early Oligocene erosional surface, with incision of deep canyons and submarine erosion of the slope (Anderson et al., 2000; Séranne, 1999). Overlying this unconformity, a westward-prograding terrigenous wedge was developed during the Oligocene to Holocene, a period of time of alternating dry and wet climatic conditions and high-amplitude/high-frequency sea level changes (icehouse period). Enhanced continental erosion supplied clastic material for the deposition of the extensive Oligocene and Miocene turbiditic fan systems (Malembo formation), which constitute reservoirs for important oil and gas discoveries in the Lower Congo Basin (Cole et al., 2000; Coward et al., 1999).

Uplift of the West African margin occurred in the Early Miocene and was synchronous with salt tectonic deformation of the post-Aptian section. These tectonic processes strongly controlled sediment delivery and distribution in the deeper 
regions of the basin. Turbiditic mass flows were focused into local grabens, whereas mud-dominated intervals were deposited elsewhere (Anderson et al., 2000). From the Early Pliocene onwards, the deeply-incised Congo Canyon confined most of the coarse fraction of the sediments supplied. Consequently, the Pliocene to Holocene succession in the Lower Congo basin (Cirques Formation, of Burwood et al. 1990) is characterized by fine-grained hemipelagic sedimentation, generally considered as a sealing unit to the Oligocene-Miocene turbiditic interval.

Cores of the Early Pliocene-Holocene sequence retrieved at the Ocean Drilling Program Leg 175 (sites 1075-1079) and Deep Sea Drilling Project Sites 364 and 365 (drill sites closest to the study area) document enhanced biological productivity related to upwelling conditions (Berger et al., 1998; Bolli et al., 1978). These were established with the onset of the Benguela Current (Late Miocene - Pliocene) on the southwest African margin. The sediments are described as diatom- and nannofossilrich clays and oozes from rain-out of suspended clays and pelagic settling of biogenic debris (Pufahl et al., 1998). Gas analysis from the cored sediments revealed high concentrations of microbial methane and carbon dioxide (103-105pmv and 104$10^{5} \mathrm{ppmv}$, respectively), with no evidence of migration of deep thermogenic hydrocarbon gases (high $\mathrm{C}_{1} / \mathrm{C}_{2}$ ratios and absence of higher molecular weight hydrocarbons) (Meyers, 1998). High total organic carbon (TOC) concentrations (between 0.9 and $5.3 \mathrm{wt} \%$, average TOC $\sim 2.5 \mathrm{wt} \%$ ) are interpreted to result from the combination of elevated palaeo-productivities and high sedimentation rates between 10 and 60cm/k.y., which improve preservation of the organic matter (Berger et al., 1998; Pufahl et al., 1998).

The Pliocene unit is pervasively deformed by polygonal faults (Cartwright, 2011; Cartwright and Dewhurst, 1998). The formation of ubiquitous seabed pockmarks and furrows offshore Angola has previously been linked to these 
polygonal faults, and some authors consider that these discontinuities acted as fluid migration conduits (Gay et al., 2007; Gay et al., 2006b). However, the results of this study contradict the assumption of polygonal faults acting as fluid migration pathways. In some cases, initial fluid expulsion episodes and pockmark genesis is interpreted to pre-date the polygonal faulting process ('bulls-eye' pockmarks of Andresen \& Huuse, 2011; Morgan et al., 2015), which is confirmed by our observations on 'bulls-eye' pockmarks present in the study area.

\subsection{Shallow seismic stratigraphy}

The seismic stratigraphy of the study area is divided into three main seismicstratigraphic units: 1, 2, and 3 (fig. 2 and 3). The stratigraphic interval of interest for this study covers the shallow-most seismic Units 2 and 3 (fig.3), which correlate to the successions of Oligocene-Miocene and Pliocene-Holocene age, respectively.

Unit 1 is characterised by laterally continuous, sub-parallel to parallel reflections of very low to moderate amplitude, which is mostly associated with finegrained deposits. Occasional reflections of higher amplitude may indicate deposition of coarser sediments. Local wavy reflections of low sinuosity represent sediment waves with upslope migration. This unit is interpreted to comprise hemipelagic deposits intercalated with minor turbiditic lobes and sparse contourite drifts, confined within the mini-basins. The contact with Unit 2 above is an erosional unconformity.

Unit 2 is characterised by sub-parallel to chaotic reflections of moderate to very high amplitude. It is generally thicker along the mini-basins axis, thinning and onlapping towards the flanking salt structures (fig. 2). Moderate to low amplitude chaotic reflections present at the bottom of this unit are associated with mass- 
transport deposits which are intercalated with thin laterally continuous turbidites (moderately high amplitude reflections). The top succession of Unit 2 exhibits continuous high to very high amplitude reflections related to axial submarine channels and less confined clastic deposition (including channel levees), interbedded with hemipelagic intervals (figs. 2 and 3).

Unit 3 is characterised by laterally continuous and parallel reflections of very low to moderate amplitude, representative of fine-grained hemipelagic deposition. Reflections of slightly higher amplitude in this succession may be associated with the deposition of coarser grain size material (Gay et al., 2007), possibly related to laterally continuous turbidites. Similarly to Unit 2, Unit 3 has maximum thicknesses along the axis of the mini-basins and thins towards the flanking salt structures, exhibiting onlapping reflection configurations (fig. 2).

Although the shallow seismic stratigraphy of the Lower Congo Basin can be summarised by the units described above, the mini-basins presented in this study show variations in the sedimentation style throughout time due to different topographic confinements produced by the salt structures. The mass-flow channels that are generally described in the literature for the Oligocene-Miocene succession (Unit 2) (Anka et al., 2013) are absent in mini-basin 2 (fig. 3). In fact, the whole shallow stratigraphy of mini-basin 1 is characterised by hemipelagic deposition, covering the entire time span between late Paleocene (top of Unit 1) to the present day (modern seabed). However it is possible to correlate the top and base reflector markers of seismic-stratigraphic Unit 2 between the adjacent mini-basins, where the dividing salt ridge does not pierce the entire overburden (NE limit of the study area). There is no marked transition between Units 2 and 3, although some reflections exhibit enhanced amplitude along the basin axis and are interpreted as possible unconfined turbidites. 
Two mass-transport deposits (MTDs) are observed flanking the salt ridges in the study area within Unit 3. Their relatively short lateral extent, geometry and good preservation of their internal reflections indicate localised remobilisation of the shallow-most layers of Unit 3, most likely caused by slope instability produced by recent salt growth.

\section{Layer-bound faults in Unit 3}

Strata within the middle interval of Unit 3 are pervasively deformed by small normal faults. These faults exhibit a wide range of planform geometries in minibasins 1 and 2. A polygonal arrangement is mapped in the central regions of minibasin 1 where faults strike at a variety of azimuths, defining a network of polygons made of short fault segments up to $640 \mathrm{~m}$ in length (fig. 4). However, this pattern changes quite dramatically towards the margins of the mini-basins. The distinctive polygonal character is abruptly lost in the proximity to salt bodies, where faults strike orthogonally to these structures and exhibit longer trace up to $3400 \mathrm{~m}$ in length (fig. 4).

The fault pattern in mini-basin 2 is dominated by strong alignment of fault strikes orthogonal to the margins, and an almost uni-directional pattern across the basin axis (fig. 4). In the central areas of this mini-basin, adjacent fault segments commonly interact to form relay ramps. In cross-section the layer-bound faults of mini-basins 1 and 2 are generally planar and very steep (with dips ranging from $50^{\circ}$ to $70^{\circ}$ ). They are confined vertically in their extent to the strata between horizons $\mathbf{C 1}$ and $\mathbf{C 3}$ (fig. 3 and 5), hence being interpreted as layer-bound faults. The highest displacements are concentrated in the central sections of the fault surfaces, reaching up to $21 \mathrm{~m}$. The faulted interval exhibits variable thickness, ranging between $31 \mathrm{~ms}$ and $285 \mathrm{~ms}$ TWT. It has a wedge geometry and thins towards the basin rims, where 
the majority of the constituent faults dip upslope (towards the thin end of the wedge). The upper limit of the interval is marked by the same reflection in both minibasins, i.e. horizon $\mathrm{C} 1$ (fig. 3). This is interpreted to represent the time at which the layer-bound faulting system became inactive. The base of the interval gradually decreases in depth as it thins towards the flanks of the mini-basins (fig. 3 and 5).

The layer-bound fault system exhibits many of the characteristics of polygonal fault systems, albeit with some considerable deviations from what could be regarded as the norm for polygonal fault systems worldwide (Cartwright and Dewhurst, 1998). The classical polygonal pattern is observed in central areas of mini-basin 1, but on its rims the faults are strongly polarised in their strikes and approximately orthogonal to salt structures. Similar fault patterns were recognised by Carruthers (2012), who describes polygonal fault systems polarised into strongly radial faults around salt diapirs. Carruthers (2012) argued that the radial and polygonal discontinuities are the same fault set but affected by local stress polarisation. Therefore by analogy, the orthogonal orientation of the faults described in this study may result from local stress field perturbations either related to salt emplacement/growth or consequent changes in topographic gradient (or a combination of both). We refer to these fault arrays as polarised polygonal faults (PPFs). PPFs occur in regions surrounding salt walls that are affected by local anisotropic stress fields, confined to areas inside a transition boundary of $1315-3170 \mathrm{~m}$ radii (average $=235 \mathrm{Om}$ radii). Polygonal faults occur in areas outside the transition boundary, where the horizontal stress field is isotropic (Carruthers, 2012, Cartwright, 2011). Due to the close proximity of two adjacent salt structures, the transition boundaries of the limiting salt walls of minibasin 2 overlap, preventing the development of polygonal fault arrays, and instead resulting in a unidirectional fault array. 
One notable feature of the distribution of the PPF system is that it is absent in a region along the western rim of mini-basin 2, as PPFs die out laterally where a slight decrease in seismic amplitudes is observed. This change in amplitude response and fault behaviour may be due to lateral lithological variations, such as deposition of coarser sediments or subtle changes in mineralogy, which may not be suitable for polygonal faulting formation (Cartwright, 2011). Thinning of the basal strata of the tier observed in this part of the mini-basin could also prevent fault nucleation and propagation, if polygonal faulting is initiated within this package. However it is possible that in this region (polarised) polygonal faulting is of a magnitude that the faults are not imaged, i.e. below the seismic resolution limit.

\section{Fluid flow features}

A variety of fluid flow features are developed within the shallow-most hemipelagic sediments of Unit 3. In the study area, vertically focused fluid flow features include pockmarks and pipes. More laterally extensive fluid flow processes are represented by bottom simulating reflections (BSRs) associated with gas hydrates, and isolated high amplitude reflections (bright spots).

\subsection{Pockmarks}

The seafloor of the surveyed region is highly saturated in pockmarks, with $5 \%$ of its area (approx. $80 \mathrm{~km}^{2}$ ) occupied by 3410 of these fluid expulsion features. Seabed pockmarks occur within a wide range of water depths, from 1830m to 2250m below sea-level. They are recognized as circular to elongated depressions related to erosion of underlying reflections (Judd and Hovland, 2007). Seabed pockmarks occur mostly within the salt mini-basins, with densities varying between $<1$ and 17 
pockmarks per $\mathrm{km}^{2}$. Few pockmarks are observed above salt ridges. Pockmark size ranges from $45 \mathrm{~m}$ to $665 \mathrm{~m}$ in diameter (length of long axis; average $=185 \mathrm{~m}$ ), and from a few meters to $36 \mathrm{~m}$ in depth (average $\approx 5 \mathrm{~m}$ depth). No seismically resolvable onlap or drape infill has been observed for the seabed pockmarks.

Buried pockmarks representing paleo fluid expulsion events are sporadically observed within mini-basin 1 . Their stratigraphic occurrence is limited to certain seismic reflections within the polygonal-faulted interval of Unit 3 (fig. 5). They occur in spatial associations of vertically stacked paleo-pockmarks separated by intervals of drape and onlap fill, and are located at the centre of polygonal fault cells. The pockmark morphology, stratigraphic occurrence, and spatial relationship to polygonal faults which concentrically surround a pockmark depression are similar to those previously described as 'bulls-eye' pockmarks by Andresen and Huuse (2011) and which were the subject of a recent structural analytical study (Morgan et al., 2015). The formation process, timing and source of fluids for the genesis of the paleo-pockmarks are thoroughly discussed by these authors. Our observations support the interpretation that these paleo-pockmarks predate the formation of the polygonal fault system affecting the surrounding strata. For the present study however, only the latest episode of fluid expulsion is considered, focusing on understanding the distribution of seabed pockmarks.

\subsection{Pipes}

Seabed pockmarks are often associated with pipes, consisting of narrow zones of vertically stacked high amplitude anomalies, occasionally exhibiting disrupted internal reflections (fig. 6). Considered as seal bypass systems, pipes occur at leak-off points for overpressured pore fluids and promote cross-stratal focused fluid flow (Cartwright et al., 2007; Løseth et al., 2009; Cartwright and Santamarina, 2015). In 
the study area pipes are mostly observed in mini-basin 2 and are stratigraphically restricted to Unit 3, with their vertical extent varying between $38 \mathrm{~m}$ and $170 \mathrm{~m}$ (average 110m height). In planform pipes are generally circular, with diameters ranging from $57 \mathrm{~m}$ to $145 \mathrm{~m}$ (average $95 \mathrm{~m}$ wide). Slenderness ratios (height/diameter; Cartwright and Santamarina, 2015) vary from 0.49 to 2.44 . In total, 570 vertically stacked amplitude anomalies were identified in mini-basin 2, representing the largest array of pipes yet identified in a single geological province.

The reflection amplitudes within pipes are generally higher than the background reflectivity of the hosting sediments, and localised amplitude anomalies are generally marked by abrupt lateral changes of amplitude. The lower reflections within pipes commonly display upward convex geometries, up to the top of the polygonally-faulted tier (horizon C1; figs. 6 and 7). Above this and towards the seabed, pipes exhibit a sag geometry with downward (concave) deflection of reflections. All pipes are observed to terminate upwards at seabed pockmarks. However, internal structures are better imaged and resolved in pipes with diameters wider than the limit of seismic resolution $(>25 \mathrm{~m})$. The widest pipes reach up to 144 $\mathrm{m}$ in diameter and often exhibit disrupted internal reflections and loss of coherency towards the top, with sharp 'sags' delimiting the lateral margins. Narrow pipes have gently curving deflections.

Recognition of the basal structure of pipes is crucial for constraining the location of the source of fluids (Moss \& Cartwright, 2010). It is interpreted here that the base of stacked amplitude anomalies marks the horizon from which pipes emanate. Based on this, a histogram was constructed of the stratigraphic position of the base of the 570 pipes identified in mini-basin 2 (fig. 7). The vast majority of pipes (46.0\% of measured pipes) originate within the seismic interval between horizons $\mathbf{x}$ (17 to 113mbsf, 20-135ms TWT bsf) and C2 (42 to 172mbsf, 50-205ms TWT bsf), up 
to $32 \mathrm{~m}$ ( $38 \mathrm{~ms}$ TWT) thick. Seismic horizon $\mathbf{x}$ is characterised by a soft reflection (decrease in acoustic impedance) whose amplitude and lateral continuity is highly variable. The remaining columnar amplitude anomalies (54.0\%) originate at various levels within an interval up to 207 ms TWT thick, 3 to 204 m below the seabed. Amplitude anomalies rooted below the interval x-C2 (between horizons r3 and r6) comprise $29.3 \%$ of measured pipes, and shallower pipes rising above horizon $\mathbf{x}$ (between horizons $\mathbf{r 1}$ and $\mathbf{r 2}$ ) compose $24.7 \%$ of total pipe population. In general, pipes are identified where the highest amplitudes are observed for their basal reflections. Beneath horizon r6 there is no disruption or amplitude enhancement that may be attributed to the presence of focused fluid flow features. Pipes terminate at the seabed at the centre of their associated pockmark depression. The bases of pipes are much harder to define in the region where polarised polygonal faults are observed. Imaging problems associated with faults introduce local amplitude variations, and these can be sometimes confused with pipe-related anomalies. This issue is especially pertinent for pipes apparently rooted below reflector C2: the source of these pipes may be in fact at shallower intervals, as the close proximity of amplitude anomalies associated to PPFs cannot be distinguished from the pipe base anomaly. For pipes rooted above reflector $\mathbf{C 2}$, the positions are considered to be accurate to \pm 2 seismic reflections.

Although composed of stacked amplitude anomalies (c.f. Ho et al., 2012), pipes are rarely strictly vertical $\left(90^{\circ}\right)$ features. Instead most pipes exhibit a slight angle with the vertical, typically quasi-perpendicular to the slope/seafloor. In MB2, pipes that occur on the western side of the mini-basin dip $45^{\circ}$ to $86^{\circ}$ towards $\mathrm{W}-\mathrm{NW}$, whereas pipes on the eastern side dip $40^{\circ}$ to $86^{\circ}$ towards E-SE. The opposite dipping direction of pipes in opposite sides of the mini-basin and their angle with the seafloor 
suggest that pipes were rotated after they formed, most probably by basin tilting due to recent salt growth. However, it is possible that overpressured fluids were expelled via a non-vertical migration path, exploiting pre-existing sub-seismic discontinuities in the hosting stratigraphy.

A critical observation of pipe distribution is that pipe occurrence is spatially limited to the area of MB2 where the interval between horizons $\mathbf{x}$ and $\mathbf{C} 2$ is present. Similarly, seabed pockmarks are not observed outside the area covered by this interval. Remarkably, the longest pockmark alignment in the study area (10km length, composed of 35 seabed pockmarks) is vertically above the pinch-out of the same interval (fig. 8), where fluids are most likely to accumulate (by lateral and vertical migration). Together with the results obtained from the pipe base histogram (fig. 7), these observations imply that the interval $\mathbf{x}$-C2 within Unit 3 is the sedimentary package from which the fluids involved in pockmark formation were stored prior to their expulsion at the modern seabed. The pinch-out of this interval is characterised by low amplitude (almost transparent) internal reflections onlapping onto the base of horizon $\mathbf{x}$. It is possible therefore that this specific low amplitude package may be composed of sediments that were involved in supplying the fluids for the pockmark formation process.

\subsection{BSRs and gas hydrates}

Semi-continuous reflections of negative polarity and moderate to strong amplitude are observed to crosscut the shallow stratigraphy. The present day depth

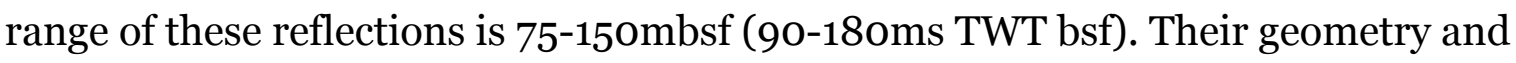
phase is consistent with bottom-simulating reflections (BSRs) associated with the base of the gas hydrate stability zone (GHSZ), as previously described for deepwater 
settings offshore West Africa (Cunningham and Lindholm, 2000; Gay et al., 2006b). The strength of these reflections decreases laterally, and they are not observed within salt mini-basins where bedding is conformable to seabed morphology. Local brightening of BSRs and elevation of their position relative to the seafloor is observed in faulted areas of the salt anticlines, where salt is closer to the seabed, and when underlain by high-amplitude turbiditic channel deposits. The presence of localised development of a gas hydrate-related BSR implies a sufficient methane flux was present at least locally in the study area.

\section{Spatial analysis of fluid flow features}

The most striking features observed on the seabed of the surveyed area are the extraordinary density and total number of pockmarks (>3410), their wide variability in size, and their remarkable distribution patterns. Seabed pockmarks are commonly arranged in a linear fashion, forming trails or alignments of up to $10 \mathrm{~km}$ in length. The phenomenal abundance of pipes and pockmark trails in the region provides a unique opportunity to analyse their distribution employing spatial statistical methods, which may contribute to the understanding of the migration pathways associated to this fluid flow system.

\subsection{Pipe source distributions}

To analyse the distribution of the 570 pipes observed in MB2, their spatial coordinates were taken at the centre of their basal amplitude anomaly. The total population of pipes was subdivided into three subpopulations according to the source intervals separated by the distinctive frequency peak at the interval $\mathbf{x}-\mathbf{C 2}$ observed on the pipe source histogram (fig. 7). Pipe groups AAI, AAII and AAIII 
comprise conduits rising from intervals r1-r2, $\mathbf{x}-\mathbf{C 2}$, and r3-r6, respectively. Amplitude anomalies rooted within interval r3-r6 (AAIII) occur exclusively in faulted areas, whereas pipes AI and AAII (intervals r1-r2 and $\mathbf{x - C 2}$ ) are distributed throughout the mini-basin, regardless of the presence or absence of seismically resoluble layer-bound faults (PPFs) (51.1\% of pipes AAII occur in non-faulted areas, and the remaining $48.9 \%$ on faulted regions). Average nearest neighbour analysis conducted on the total population of pipes and on each of the three subpopulations show that the distribution of pipes is considered clustered at the $99 \%$ statistical significance level (see table 1). These results however do not shed light on if (and how) the source and position of individual pipes is related to other neighbouring pipes.

Moss and Cartwright (2010) used Anselin Local Moran's I cluster and outlier analysis to statistically assess the spatial distribution of pipe formation in distinct time phases. The same approach is used here, but adapted in order to determine whether pipes with a base in a particular source interval are preferentially surrounded by pipes sourced either from the same or from a different interval. Pipes that are considered statistically significant outliers (i.e., pipes that have a statistically significant different source value from their neighbours) and clusters (pipes surrounded by others with a statistically similar source) have a local Moran's I (Ii) $Z$ scores $<-2$ or $>2$, respectively. Pipes that are not statistically significant (nonoutliers) hold Ii $Z$ scores between -1 and 1. The results obtained from this method are shown in figure 9. Statistically significant outliers (dark blue circles) and clusters (red circles) occur almost exclusively in faulted areas, whereas pipes with no statistically significant source value are most observed in non-faulted regions (green circles). The null hypothesis that there is no systematic pattern to the spatial distribution of pipe sources is rejected at the $>95 \%$ confidence level for faulted 
domains, but not for the non-faulted corridor. The results from the Moran's I spatial analysis suggest pipe source distribution is influenced by the presence or absence of PPFs.

\subsection{Pockmark distributions}

The statistical detection of point alignments employed in this study (the continuous sector method of Hammer, 2009) is used to numerically corroborate the pockmark patterns that stand out to the eye, and to determine whether these result from random chance or are in fact controlled by underlying discontinuities, as implied by the results of the pipe source spatial analysis above.

All seabed pockmarks observed in mini-basin 2 were mapped (comprising a total of 1086 pockmarks), and the spatial coordinates of their centre were taken at the deepest point within each depression.

By overlaying the centre points of seabed pockmarks to a dip map of horizon C2, it is possible to compare the spatial distribution of these pockmarks with the underlying polarised polygonal faults (fig. 10). Two sets of pockmarks were defined according to where they occur in relation to faults: set A (283 pockmarks, green dots) includes pockmarks located in areas not affected by any seismic resolvable discontinuity, and set B (803 pockmarks, pink dots) comprises pockmarks that occur within faulted regions. Visually, set B pockmarks tend to be arranged in a linear fashion striking parallel to the underlying faults, whereas the distribution of set A pockmarks appears to be more erratic (fig. 10).

The results of the alignment detection by the continuous sector method (Hammer, 2009) employed for sets A and B are shown in figures 1obi and 1obii, respectively. Defining a circular zone around each point of radius $r=500 \mathrm{~m}$ (radial length), this method extracted 30 aligned segments amongst set A pockmarks, and 
322 aligned segments for set B (at a significance level of $p<0.5$ ). The rose diagrams in these figures show the orientation of the aligned segments obtained for both sets. A Rayleigh test on the extracted alignments shows no preferred direction of set A alignments $(p=0.74)$, whereas set B exhibits a highly significant and marked preferred direction NNW-SSE (mean direction $\left.=156.34^{\circ}\right)(p<0.001)$. Using the Watson-Williams (equal mean) and Mardia-Watson-Wheeler (equal distribution) tests for analysing the distributions of two samples of directional data (Mardia, 1972 in Hammer et al., 2001), the calculated preferred orientation of set B pockmark alignments was compared to the strikes of the 601 underlying polarised polygonal faults. A highly significant $p$ value $(p<<0.001)$ was calculated on both tests, supporting the inference that there is a genuine spatial relationship between seabed pockmark distributions and polarised polygonal fault patterns.

First order spatial statistics (average nearest neighbour) at the $99 \%$ significance level applied to set A pockmarks show a tendency towards a dispersed distribution $(\mathrm{Rn}=1.10, \mathrm{z}=3.20)$, whereas set $\mathrm{B}$ pockmarks are considered clustered $(\mathrm{Rn}=0.75, \mathrm{z}=-15.16)$. However, this method only provides a general distribution overview based on average values with a single search radius, which is not precise enough to assess pipe distributions at the basin scale.

To examine patterns at multiple search radii, the more robust Multi-distance spatial cluster analysis (Ripley's K Function) is employed. Ripley's statistics $(L(d))$ applied to set A pockmarks revealed a tendency towards dispersion or anti-clustering between 25-200m of distance between nearest neighbours, tending to be clustered for distances between 250-3000m. The same analysis showed a lateral inhibition (dispersion) of set B pockmarks up to a distance of $175 \mathrm{~m}$, and a tendency towards clustering for distances larger than 200m. These results suggest an exclusion zone of $<200 m$ around each pockmark where no other pockmark will form, which may 
reflect the existence of a fluid drainage area - the area around the base of each feeding pipe in which the source interval was depleted of fluids to produce a pockmark. This is in agreement to the "pockmark drainage cell" described by Moss and Cartwright (Moss, 2010; Moss and Cartwright, 2010).

From ca. 30oom onwards, $L(d)$ falls below the high confidence interval, becoming flattened in the manner expected from complete spatial randomness (CSR). As such, for distances greater than 300om, the position of a given pockmark has no influence on the location at which a new pockmark will form.

\subsection{Pockmark-pipe-fault relationship}

In cross-sections orthogonal to pockmark alignments of set $\mathrm{B}$ it is possible to observe the geometrical relationship between feeding pipes and PPFs (fig. 11). Invariably these pipes occur on the hanging wall blocks of PPFs, the majority of which rise from where faults intersect the strata between reflectors $\mathbf{x}$ and $\mathbf{C 2}$. Although there are some amplitude anomalies adjacent to faults, pipes and faults are separate features. If PPFs were to serve as migration pathways for the fluids involved in pockmark formation, pipes might be expected to rise from the upper tips of these faults. Instead, pipes form and develop where the interval $\mathbf{x}$-C2 is intersected by fault surfaces, explaining the offset observed between PPF traces and pockmark alignments. Thus, pockmarks lie above the footwall cut-offs of the inferred stratal position of the source package.

\section{Discussion - structural controls on pockmark alignments}

Having established the nature of the pockmark distributions in the study area, an underlying aim of this discussion is to examine how these alignments can be used 
to develop a model for plumbing systems as a whole. The next sections address the following issues:

1) Fluid migration routes: what types of conduit are present in the near shallow subsurface?

2) Source and type of fluids responsible for pockmark formation: is it gas or pore fluid and is it sourced shallow or deep from within the mini-basin fills?

3) Controls on pockmark spacing along alignments: does this give clues as to the plumbing system?

4) Driving and trigger mechanisms: what caused this episode of focused fluid expulsion, and what is the significance of the timing of pockmark formation for the underlying causal mechanism?

\subsection{Fluid conduits}

Pockmarks result from the expulsion of fluids at the seabed, and it is widely assumed that the ascending fluids are focused along a columnar conduit below (Cartwright et al., 2007; Ho et al., 2012; Judd and Hovland, 2007; Løseth et al., 2009; Løseth et al., 2011; Moss and Cartwright, 2010). The seismic expression of the pathways used for these fluids to migrate through the sedimentary succession can vary greatly. Most seabed pockmarks in the study area show no underlying amplitude anomalies that could be related to the presence of a feeding conduit. However, all pipes identified within MB2 terminate at the centre of a seabed pockmark. The spatial relationship observed between these two fluid flow features imply that pipes are the conduits for the fluids expelled at the seabed during pockmark formation. As such, every seabed pockmark may reasonably be expected to be associated with an underlying feeding pipe. Pipes with clear seismic imaging as columnar zones of distorted reflections combined with stacked amplitude anomalies may reflect local 
cementation or deformation of strata during fluid flow, or be evidence of presently stored fluid within them (Andresen, 2012; Ho et al. 2012). The absence of a pipe below a pockmark is suggested here to be the result of the resolution limitations of the $3 \mathrm{D}$ seismic data. In cases where no pipe is imaged, we suggest that pipe width must fall well below the limit of seismic resolution, or the physical properties of the material inside the pipe do not yield acoustic impedances that contrast with the hosting sediments (Løseth et al., 2011).

The pipes observed in the study area are similar (though generally smaller) to many previous examples of pipes interpreted from 3D seismic data (see Cartwright and Santamarina (2015) for review) in which a mechanism of fracture driven, crossstratal migration of methane is implicated in their formation. The presence of methane in the fluids that first transited to the seabed via the pipe conduits is thus consistent with their seismic expression in the study area. Note that this does not exclude a significant contribution from ascending pore fluids.

\subsection{Source and type of fluids}

In the present-day fluid flow regime of the Lower Congo Basin (expressed by seabed pockmarks), hydrocarbon fluids are typically considered to be sourced from reservoirs within the turbiditic fans of Oligocene-Miocene age (Gay et al., 2006a), or to be focused flow of thermogenic fluids along salt flanks (Andresen and Huuse, 2011; Gay et al., 2007). However, such a deep source of potentially thermogenic hydrocarbons is unlikely to explain seabed pockmark distributions of the type and extent presented in this study. The seabed of both salt mini-basins presented here is highly saturated in pockmarks, being almost entirely covered by these depressions. The large extent of these pockmark fields implies a laterally continuous reservoir of relatively uniform physical properties, which stored the fluids that were to be 
intimately involved in their formation process. Such a laterally continuous extensive reservoir could be expected to be located at shallow depths. More deeply-sourced fluids would have more likelihood of being focused along complex migration pathways within the sedimentary succession, exploiting in their ascent a combination of stratal and structural permeable pathways, and thus might be expected to yield more localised distributions. The most likely deeper reservoirs for the seabed pockmarks would be expected to be the deepwater channelized units of Unit 2 that can be seen within some of the mini-basin fills in the area (e.g. in MB1, fig. 3) but their absence in MB2 where large numbers of pipes and pockmarks are observed argues against this unit acting as the principal immediate source for the pockmarks. The absence of pockmarks directly above salt ridges and along the mini-basin rims also argues against a deeper source (c.f. Andresen and Huuse, 2011).

Pipes that fed the seabed pockmarks are observed to be stratigraphically limited to the shallow-most seismic Unit 3 (fig. 7), strongly supporting the interpretation of a shallow reservoir within part or all of this unit. The histogram of pipe root horizons (fig. 7) shows that pipes root at several levels within Unit 3, but with a majority in the interval between horizons $\mathbf{x}$ and C2. By overlying pockmark loci with the amplitude map of interval $\mathbf{x}-\mathbf{C 2}$, it is clear that seabed pockmarks only occur within the limits of the area where this layer was deposited (fig. 8). It is also interesting to note that, non-faulted regions of MB2 closely match areas of enhanced amplitudes and more chaotic reflections within this interval. These amplitudes may be related to deposition of coarser sediments (possibly sands), which may act to inhibit the nucleation and initial propagation of polygonal faults (Cartwright, 2011). This corridor of enhanced amplitudes/possible sand may be related to confinement of coarser sediments transported by turbidity currents. It could also result from bottom-current sorting at the time of deposition, especially taking into account the 
concave shape of MB2 (higher velocity bottom-currents near the central parts of the mini-basin where fine sediments are washed away, with settling of coarser fractions to be deposited in low velocity areas (mini-basin steeper rims)).

An intriguing observation is that all the BSRs observed in salt anticline flanks occur at depths similar to the depth range of reflector $\mathbf{x}$, suggesting a possible connection between the hydrate stability zone (present day) and the most likely source interval for the fluids responsible for pockmark formation. Identification of any putative BSR within the mini-basin is difficult because the hemipelagic fill is concordant to the seafloor. Nevertheless, it is plausible that reflector $\mathbf{x}$ marks the base of the gas hydrate stability zone (GHSZ). If so, then it is conceivable that pockmark formation may be associated with gas hydrate dissociation and/or expulsion of free gas beneath the GHSZ. Methane produced from the dissociation of gas hydrates could then be considered as the main fluid involved in seabed pockmark formation. Although speculative, the dissociation of gas hydrates and subsequent gas expulsion may have been triggered by alterations of the PT regime (shifting away from hydrate stability conditions) caused by salt growth and ensuing topographic changes. Since we have no geochemical data, it is not possible to interpret the origin of the gas that is involved in the development of a BSR in this area, but we note that in nearby areas both biogenic and thermogenic sourcers have been inferred for the gas trapped in the hydrate layer (Andresen and Huuse, 2011).

It is also plausible that a reduction of pressure by a rapid sea level drop could either have triggered gas release from hydrates or from solution in pore fluids in the source interval (Hermanrud et al., 2013; Riboulot et al., 2013).

\subsection{Controls on pockmark distribution - the role of polarised polygonal}

\section{faults}


Seabed pockmarks have been commonly observed to be aligned in a linear fashion, forming trails up to 10km in length. Linear pockmark arrays have been shown to reflect the distribution of underlying structural or stratigraphic discontinuities controlling the establishment of pathways for upward fluid migration (structural discontinuities: Gay et al., 2007; Pinet et al., 2009; stratigraphic discontinuities Gay et al., 2006a; Pilcher and Argent, 2007).

The structural controls on pockmark alignments described in this study add to the previous examples of pockmark alignments noted above, with the novel aspect here being the inter-relationship between polarised polygonal faults and pockmarks (fig. 10). In contrast to some previous studies, however, we find no evidence that the polygonal faults acted as conduits. The spatial alignment is instead interpreted here as a control by the fault plane on the nucleation position of the pipe feeing the pockmark (figs. 11 and 12), with the critical locus being at the intersection of the fault plane with the likely fluid source interval. This argument is supported by the recognition that seabed pockmark formation is not specifically linked to the polygonal fault system, simply because pockmarks are also present in areas not affected by polygonal faulting. Also, there is a considerable time period (estimated to be between 192 k.y. - 1.15 M.a.) between the end of the active period of polygonal faulting and the timing of pockmark formation, as evidenced by the $135 \mathrm{~ms}$ TWT (115m) thick hemipelagic succession deposited above the top tier of the polygonaly faulted interval (reflector C1).

\subsection{Implications for the shallow plumbing system}

Based on the evidence derived from the seismic interpretation and statistical analysis, we suggest the following evolutionary model for the seabed pockmarks in the study area: 
1. Pockmark formation in MBs 1 and 2 occurred within the past few thousand years, since all the pockmarks have a clear expression at the seafloor, and none of the pockmarks show any resolvable signs of being buried by recent sediments.

2. The statistical data on distribution is consistent with this being a single episode of fluid expulsion, since there is clear evidence for an exclusion zone whereby the formation of one pockmark inhibits neighbouring pockmarks from forming within the exclusion zone. This in turn suggests a period of fluid expulsion whose duration was short enough to prevent any resetting of the hydrodynamic boundary conditions that led to the venting.

3. The source of the fluids involved in pockmark formation in this event was most probably from within Unit 3, and from the pinch-out relationship was most likely located stratigraphically between reflectors $\mathbf{x}$ and C2. The seismically resolved conduits between the source and the seabed pockmarks are pipe-like structures similar to fluid escape pipes observed in many other basins. From their stacked amplitude anomaly patterns of these conduits, the fluids transported through these conduits most probably included free gas, which is consistent with standard models for pockmark formation.

4. The trigger for the fluid expulsion event is unknown, but from the coincidence between the observed depth to reflector $\mathrm{x}$ and the BSR observed on the minibasin flanks, it is suggested that gas hydrate dissociation may have been involved in liberating methane and its focused expulsion to the seabed led to the formation of the pockmarks. Hydrate dissociation may have been triggered by the dramatic change in sea level at the end of the last glacial maximum (c.f. Sultan et al., 2004).

5. The alignments of pockmarks and pipes in the area of MB2 affected by polarised polygonal faults is seen here as an exploitative relationship, whereby the locus of pipe formation was at the intersection of the fault plane with the fluid source layer. There 
is no evidence that the faults acted as conduits, which is supported by the systematic offset between pockmark positions and the upper tip positions of the fault planes.

\section{Conclusions}

- 3410 seabed pockmarks have been mapped in two salt-related mini-basins (MB1 and 2) in the Lower Congo Basin, offshore Angola. Their diameters range from 45 to $665 \mathrm{~m}$, and they have an average spacing of $300 \mathrm{~m}$. Of these, 570 pockmarks are underlain and fed via pipe-like conduits that are clearly imaged on the 3D seismic data.

- The pockmarks exhibit interesting local alignments in their distribution that can be clearly shown to be related to polarised polygonal faults. The uniformity of their statistical distribution argues for a shallow depth below the seabed for the source interval that supplied the fluids forming the pockmarks.

- The distribution of the pockmarks in MB2 suggests that the primary storage interval sedimentary package $\mathbf{x}-\mathbf{C} \mathbf{2}$.

- The stacked amplitude anomalies associated with the seismically imaged pipes is linked to free gas migration. The composition and ultimate origin of the free gas is unknown.

- Spatial statistics analysis of seabed pockmarks distributions revealed that pockmark occurrence is not considered to be random at short distances to their nearest neighbours. In faulted areas of mini-basin 2, seabed pockmarks are clustered and form alignments along a preferred NNW-SSE direction, which are controlled by the underlying polarised polygonal fault patterns. 
- In non-faulted areas of mini-basin 2, seabed pockmarks do not form alignments, and their spatial distribution is considered random at distances $>3000 \mathrm{~m}$ of their nearest neighbours.

- $2^{\text {nd }}$ order spatial statistics revealed that seabed pockmarks distributions (both in faulted and non-faulted areas) tend to be dispersed or anti-clustered at short distances $(<200 m)$ of their nearest neighbours. This result suggests there is an exclusion zone of <20om around each pockmark in which no other pockmark will occur.

- Although the spatial distribution of seabed pockmarks is controlled by underlying PPFs, pockmark formation is not linked to the polygonal fault system. Pipes invariably occur on hanging-wall blocks, rising vertically from where fault planes intersect the estimated source interval - fluids at the source exploit the discontinuity, producing linear pockmark arrangements parallel to the faults.

- Pockmark formation occurred in the last few thousand years, possibly related to gas hydrate dissociation linked to sea level changes.

\section{Acknowledgements}

The authors are grateful to Statoil and PGS for providing the $3 \mathrm{D}$ seismic data and allowing the publication of this study. Schlumberger is acknowledged for the provision of seismic interpretation software. Ana Maia thanks the Fundação para a Ciência e Tecnologia (FCT) for the SFRH/BD/68286/2010 PhD grant. We thank David James, Martino Foschi, Daniel Morgan, and Davide Gamboa for many useful 
discussions. We also acknowledge the contributions of the reviewers for their constructive comments.

\section{References}

Anderson, J. E., Cartwright, J., Drysdall, S. J., and Vivian, N., 2000, Controls on turbidite sand deposition during gravity-driven extension of a passive margin: examples from Miocene sediments in Block 4, Angola: Marine and Petroleum Geology, v. 17, no. 10, p. 1165-1203.

Andresen, K. J., 2012, Fluid flow features in hydrocarbon plumbing systems: What do they tell us about the basin evolution?: Marine Geology, v. 332, p. 89-108.

Andresen, K. J., and Huuse, M., 2011, Bulls-eye' pockmarks and polygonal faulting in the Lower Congo Basin: Relative timing and implications for fluid expulsion during shallow burial: Marine Geology, v. 279, no. 1-4, p. 111-127.

Anka, Z., Ondrak, R., Kowitz, A., and Schødt, N., 2013, Identification and numerical modelling of hydrocarbon leakage in the Lower Congo Basin: Implications on the genesis of km-wide seafloor mounded structures: Tectonophysics, v. 604, no. 0 , p. 153-171.

Berger, W., Wefer, G., Richter, C., Lange, C., Giraudeau, J., Hermelin, O., and Party, S. S., THE ANGOLA-BENGUELA UPWELLING SYSTEM: PALEOCEANOGRAPHIC SYNTHESIS OF SHIPBOARD RESULTS FROM LEG 1751, in Proceedings Proceedings Ocean Drilling Program, Initial Reports1998, Volume 175, p. 505531. 
Berndt, C., 2005, Focused fluid flow in passive continental margins: Philosophical Transactions of the Royal Society A: Mathematical, Physical and Engineering Sciences, v. 363, no. 1837, p. 2855-2871.

Bolli, H., Ryan, W., Foresman, J., Hottman, W., Kagami, H., Longoria, J., McKnight, B., Melguen, M., Natland, J., and Proto-Decima, F., 1978, Angola continental marginSites 364 and 365: Initial Reports of the Deep Sea Drilling Project, v. 40, p. 357390.

Broucke, O., Temple, F., Rouby, D., Robin, C., Calassou, S., Nalpas, T., and Guillocheau, F., 2004, The role of deformation processes on the geometry of mud-dominated turbiditic systems, Oligocene and Lower-Middle Miocene of the Lower Congo basin (West African Margin): Marine and Petroleum Geology, v. 21, no. 3, p. 327348.

Burwood, R., Cornet, P. J., Jacobs, L., and Paulet, J., 1990, Organofacies variation control on hydrocarbon generation: A Lower Congo Coastal Basin (Angola) case history: Organic Geochemistry, v. 16, no. 1-3, p. 325-338.

Carruthers, T., 2012, Interaction of polygonal fault systems with salt diapirs: Cardiff University.

Cartwright, J., 2011, Diagenetically induced shear failure of fine-grained sediments and the development of polygonal fault systems: Marine and Petroleum Geology, v. 28, no. 9, p. 1593-1610.

Cartwright, J., and Dewhurst, D., 1998, Layer-bound compaction faults in fine-grained sediments: Geological Society of America Bulletin, v. 110, no. 10, p. 1242-1257.

Cartwright, J., Huuse, M., and Aplin, A., 2007, Seal bypass systems: American Association of Petroleum Geologists Bulletin, v. 91, no. 8, p. 1141-1166. 
Cartwright, J., and Santamarina, C., 2015, Seismic characteristics of fluid escape pipes in sedimentary basins: Implications for pipe genesis: Marine and Petroleum Geology, v. 65, p. 126-140.

Cole, G., Requejo, A., Ormerod, D., Yu, Z., and Clifford, A., 2000, Petroleum Geochemical Assessment of the Lower Congo Basin, in Mello, M. R., and Katz, B. J., eds., Petroleum systems of the South Atlantic margins, AAPG Memoir 73, p. 325-339.

Coward, M. P., Purdy, E. G., Ries, A. C., and Smith, D. G., 1999, The distribution of petroleum reserves in basins of the South Atlantic margins, Geological Society Special Publication, Volume 153, p. 101-131.

Cunningham, R., and Lindholm, R., 2000, Seismic evidence for widespread gas hydrate formation, offshore West Africa: MEMOIRS-AMERICAN ASSOCIATION OF PETROLEUM GEOLOGISTS, p. 93-106.

Davies, R. J., 2003, Kilometer-scale fluidization structures formed during early burial of a deep-water slope channel on the Niger Delta: Geology, v. 31, no. 11, p. 949-952.

Fort, X., Brun, J.-P., and Chauvel, F., 2004, Salt tectonics on the Angolan margin, synsedimentary deformation processes: AAPG Bulletin, v. 88, no. 11, p. 15231544.

Gay, A., Lopez, M., Berndt, C., and Séranne, M., 2007, Geological controls on focused fluid flow associated with seafloor seeps in the Lower Congo Basin: Marine Geology, v. 244, no. $1-4$, p. $68-92$

Gay, A., Lopez, M., Cochonat, P., Levaché, D., Sermondadaz, G., and Seranne, M., 2006a, Evidences of early to late fluid migration from an upper Miocene turbiditic channel revealed by 3D seismic coupled to geochemical sampling within seafloor pockmarks, Lower Congo Basin: Marine and Petroleum Geology, v. 23, no. 3, p. 387-399. 
Gay, A., Lopez, M., Cochonat, P., Séranne, M., Levaché, D., and Sermondadaz, G., 2006b, Isolated seafloor pockmarks linked to BSRs, fluid chimneys, polygonal faults and stacked Oligocene-Miocene turbiditic palaeochannels in the Lower Congo Basin: Marine Geology, v. 226, no. 1-2, p. 25-40.

Hammer, Ø., 2009, New statistical methods for detecting point alignments: Computers \& Geosciences, v. 35, no. 3, p. 659-666.

Hammer, Ø., Harper, D., and Ryan, P., 2001, PAST—Paleontological STatistics software: Package for education and data analysis. Paleontologia Electronica.

Hempton, M., Rosen, M., Coughlin, R., Scardina, A., HAGEN, E., and NORDSTROM, D., 1990, The geology of west Africa-a regional review: American Association Petroleum Geologists Bulletin, v. 75, p. 583.

Hermanrud, C., Venstad, J. M., Cartwright, J., Rennan, L., Hermanrud, K., and Nordgard Bolas, H. M., 2013, Consequences of water level drops for soft sediment deformation and vertical fluid leakage: Mathematical Geosciences, v. 45, no. 1, p. $1-30$.

Ho, S., Cartwright, J., and Imbert, P., 2012, Vertical evolution of fluid venting structures in relation to gas flux, in the Neogene-Quaternary of the Lower Congo Basin, Offshore Angola: Marine Geology, v. 332, p. 40-55.

Hovland, M., and Judd, A. G., 1988, Seabed Pockmarks and Seepage, London, Graham and Trotman.

Judd, A., and Hovland, M., 2007, Seabed fluid flow: the impact on geology, biology and the marine environment, Cambridge University Press.

Løseth, H., Gading, M., and Wensaas, L., 2009, Hydrocarbon leakage interpreted on seismic data: Marine and Petroleum Geology, v. 26, no. 7, p. 1304-1319. 
Løseth, H., Wensaas, L., Arntsen, B., Hanken, N.-M., Basire, C., and Graue, K., 2011, 1000 m long gas blow-out pipes: Marine and Petroleum Geology, v. 28, no. 5, p. $1047-$ 1060.

Lundin, E. R., 1992, Thin-skinned extensional tectonics on a salt detachment, northern Kwanza Basin, Angola: Marine and Petroleum Geology, v. 9, no. 4, p. 405-411.

Meyers, P., 1998, Microbial gases in sediments from the southwest African margin: Proceedings of the Ocean Drilling Program. Initial reports, v. 175, p. 555-560.

Mitchell, A., 2005, The ESRI Guide to GIS Analysis: Spatial Measurements and Statistics. Vol 2. Redlands, CA: ESRI Press.

Moss, J. L., 2010, The spatial and temporal distribution of pipe and pockmark formation, PhD Thesis, Cardiff University, Unpublished.

Moss, J. L., and Cartwright, J., 2010, 3D seismic expression of km-scale fluid escape pipes from offshore Namibia: Basin Research, v. 22, no. 4, p. 481-501.

Morgan, D., Cartwright, J., and Imbert P. 2015. Marine and Petroleum Geology.

Pilcher, R., and Argent, J., 2007, Mega-pockmarks and linear pockmark trains on the West African continental margin: Marine Geology, v. 244, no. 1-4, p. 15-32.

Pinet, N., Duchesne, M., and Lavoie, D., 2009, Linking a linear pockmark train with a buried Palaeozoic structure: a case study from the St. Lawrence Estuary: GeoMarine Letters, p. 1-6.

Pufahl, P., Maslin, M., Anderson, L., Brüchert, V., Jansen, F., Lin, H., Perez, M., Vidal, L., and Party, S. S., 18. LITHOSTRATIGRAPHIC SUMMARY FOR LEG 175: ANGOLABENGUELA UPWELLING SYSTEM1, in Proceedings Proceedings Ocean Drilling Program, Initial Reports 1998, Volume 175, p. 533-542.

Riboulot, V., Cattaneo, A., Sultan, N., Garziglia, S., Ker, S., Imbert, P., and Voisset, M., 2013, Sea-level change and free gas occurrence influencing a submarine landslide and 
pockmark formation and distribution in deepwater Nigeria: Earth and Planetary Science Letters, v. 375, p. 78-91.

Rouby, D., Guillocheau, F., Robin, C., Bouroullec, R., Raillard, S., Castelltort, S., and Nalpas, T., 2003, Rates of deformation of an extensional growth fault/raft system (offshore Congo, West African margin) from combined accommodation measurements and 3-D restoration: Basin Research, v. 15, no. 2, p. 183-200.

Séranne, M., 1999, Early Oligocene stratigraphic turnover on the west Africa continental margin: a signature of the Tertiary greenhouse-to-icehouse transition?: Terra Nova, v. 11, no. 4, p. 135-140.

Spathopoulos, F., 1996, An insight on salt tectonics in the Angola Basin, South Atlantic: Geological Society, London, Special Publications, v. 100, no. 1, p. 153-174.

Sultan, N., Cochonat, P., Foucher, J.-P., Mienert, J., 2004, Effect of gas hydrates melting on seafloor slope instability: Marine Geology, v. 213, no. 1-4, p. 379-401 


\section{Figure captions}

Figure 1. Location map of the study area, showing the main domains of salt tectonic deformation offshore Angola, ODP drill sites, and the location of known wells for hydrocarbon exploration industry.

Figure 2. A) Structure map of the seafloor of the study area, and location of figures 2B, 4, 5A, 8, 9 and 10. Mini-basins 1 (MB1) and 2 (MB2) are delimited by NNE-SSW salt ridges. Seabed pockmarks are observed as circular depressions distributed throughout the mini-basins. B) WNW-ESE seismic cross-section intersecting minibasins MB1 and MB2, and the salt ridge that separates them. Units 1, 2 and 3 are shown having distinct seismic characters.

Figure 3. Seismic stratigraphy of mini-basin $1(\mathrm{MB} 1)$ and $2(\mathrm{MB} 2) . \mathbf{S b}=$ seabed (top of Unit 3); $\mathbf{C} \mathbf{1}=$ top of polygonal fault tier; $\mathbf{C 2}=$ reflector at middle of polygonal fault tier; $\mathbf{C} \mathbf{3}=$ base of polygonal fault tier; $\mathbf{M}=$ top of Unit 2; $\mathbf{L}=$ top of Unit 1.

Figure 4. Structure and dip map of seismic horizon C2. Note the contrast between polygonal fault arrangements in different areas - the central region of mini-basin 1 exhibits a typical polygonal pattern, whereas mini-basin 2 and salt margins of minibasin 1 present hybrid faults striking perpendicular to salt structures. Although minibasin 1 is pervasively affected by polygonal faulting, there are regions of mini-basin 2 absent of seismically resoluble discontinuities (ex., the south-western rim of minibasin 2 depicted here).

Figure 5. Seabed pockmarks versus subsurface bulls-eye pockmarks - seismic profiles and maps at event reflectors. A) Seismic section across mini-basin 2, showing seabed pockmarks, feeding pipes and the polygonal fault system within Unit 3. Arrows point to seabed pockmarks. Location of seismic section is in Fig. 2A. B) 
Seismic section intersecting a subsurface bulls-eye pockmark and several seabed pockmarks (black arrows) in mini-basin 1. C) Interpretation of seismic section shown in B). D) Maps of reflectors within the bulls-eye pockmark, showing its internal structure and variation with depth.

Figure 6. Seismic profiles of pipes present in non-polygonaly faulted area of minibasin 2, occurring without being associated to any seismically resoluble discontinuity. Pipe defined as columnar zone of enhanced amplitude (vertically stacked amplitude anomalies), occasionally presenting disrupted internal reflectors.

Figure 7. Pipe amplitude anomaly base reflector frequency. Each reflector in minibasin 2 was consecutively numbered from seabed. The frequency histogram displays the number of pipes that rise from a particular reflector (pipe amplitude anomaly base). Most pipe bases are located between horizons $\mathbf{x}$ and $\mathbf{C 2}$ (46\% pipes). Data collected for 570 pipes in mini-basin 2. Pipe shown in seismic section is located in the non-polygonaly faulted area of mini-basin 2, and rises from reflector C2.

Figure 8. A) RMS amplitude map of the seismic interval between reflectors $\mathbf{x}$-C2, and seabed pockmark distribution - pockmarks within mini-basin 2 do not occur in areas where the interval was not deposited. Longest pockmark alignment parallel to the salt ridge is vertically above the pinch-out of the same interval. B) Transverse seismic section of mini-basin 2, highlighting interval x-C2. C) Close-up of pinch-out areas of $\mathbf{x}$-C2, showing internal reflections and pockmark vertically above pinch-outs (turbiditic levees/confined drifts?).

Figure 9. Spatial distribution of pipes within mini-basin 2, and their relation to underlying polarised polygonal faults. 
Figure 10. A) Spatial distribution of seabed pockmarks and pipes of mini-basin 2, and their relation to underlying hybrid polygonal faults. Two sets of pockmarks were defined: set A (green dots) - pockmarks not associated to any seismic resoluble discontinuity; set B (pink dots) - pockmarks occurring at faulted regions. Visually, set B pockmarks tend to be arranged in a linear fashion, striking parallel to underlying faults, whereas set A pockmark distribution appears to be more erratic. B) Seabed pockmark alignment detection. i) Alignment detection for set A. ii) Alignment for set B.

Figure 11. Seismic profiles showing pipe position in relation to polarised polygonal fault planes in mini-basin 2 - invariably, pipes occur on hanging wall blocks, rising from where faults intersect the interval between reflectors $\mathbf{x}$ and $\mathbf{C 2}$ (fluid source).

Figure 12. Fluid flow system - model schematics.

\section{Table captions}

Table 1. Spatial distribution analysis of amplitude anomalies in MB2. Average nearest neighbour test results shown for $99 \%$ of statistical significance. $\mathrm{AA}=$ amplitude anomaly; ANN = average nearest neighbour $(\mathrm{Rn}) ; \mathrm{z}=\mathrm{z}$ score. 


\section{Shallow plumbing systems inferred from spatial analysis of pockmark}

\section{arrays}

Ana Maia ${ }^{1}$, J oseph Cartwright ${ }^{2}$, and Espen Andersen ${ }^{3}$

${ }^{1}$ Corresponding author: 3D Seismic Lab - School of Earth and Ocean Sciences, Cardiff University, Park Place, Cardiff CF10 2FQ, United Kingdom; MaiaAR@cardiff.ac.uk

2Department of Earth Sciences, University of Oxford, United Kingdom; joec@earth.ox.ac.uk

3Statoil ASA, Norway

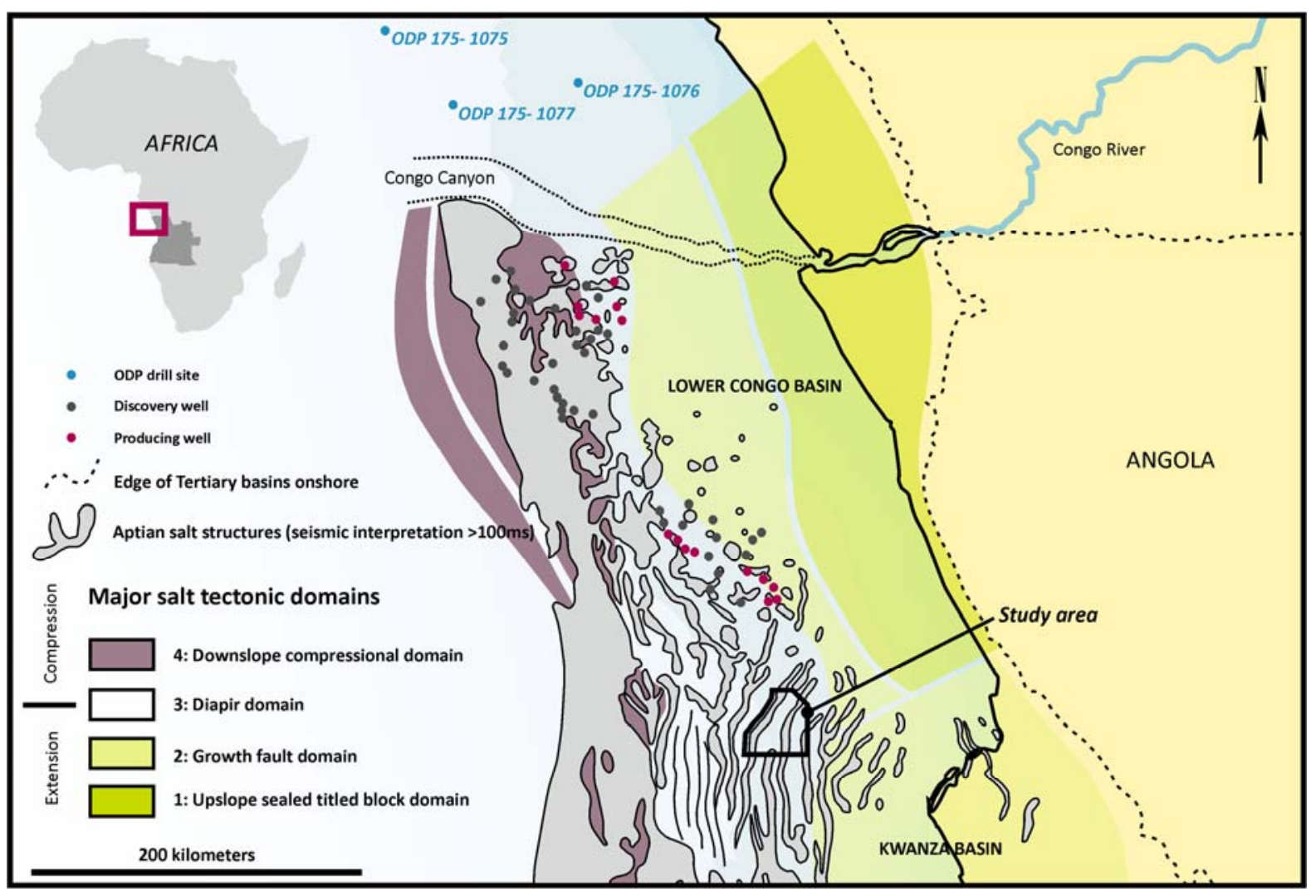

Figure 1. Location map of the study area, showing the main domains of salt tectonic deformation offshore Angola, ODP drill sites, and the location of known wells for hydrocarbon exploration industry. 
(A)

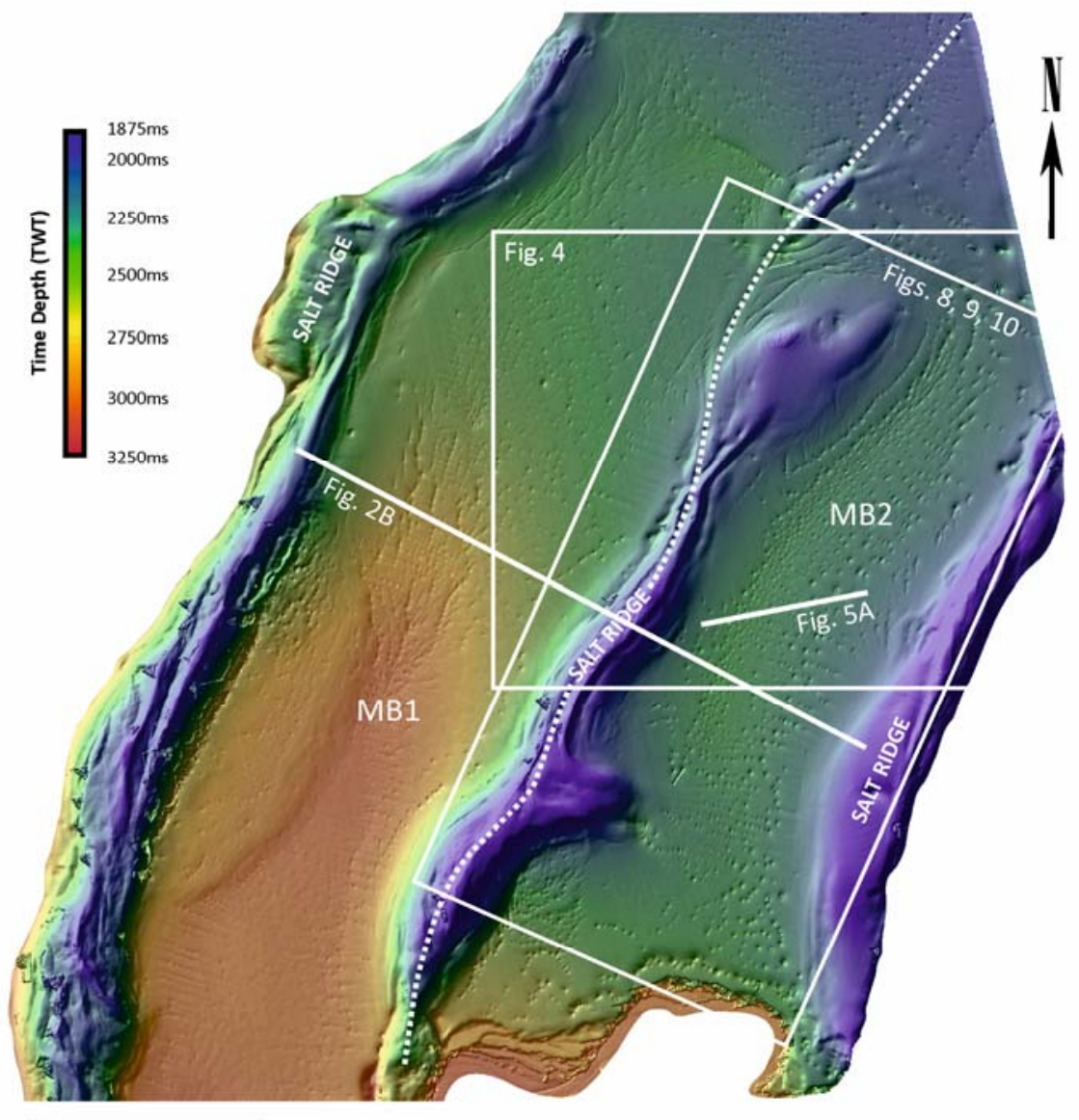

10 kilometres

(B)

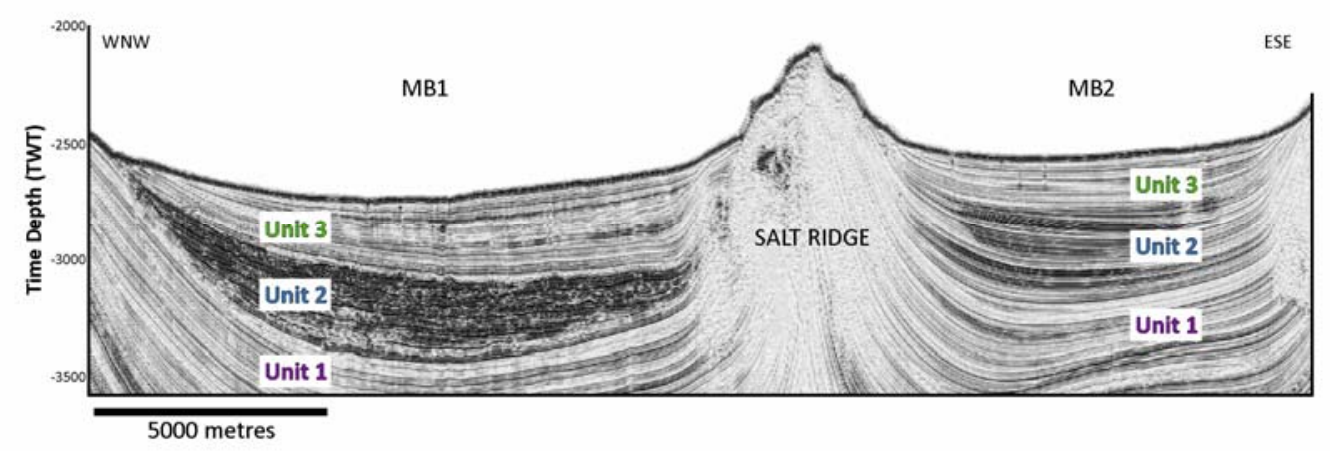

Figure 2. A) Structure map of the seafloor of the study area, and location of figures 2B, 4, 5A, 8, 9 and 10. Mini-basins 1 (MB1) and 2 (MB2) are delimited by NNE-SSW salt ridges. Seabed pockmarks are observed as circular depressions distributed throughout the mini-basins. B) WNW-ESE seismic cross-section intersecting mini-basins MB1 and MB2, and the salt ridge that separates them. Units 1, 2 and 3 are shown having distinct seismic characters. 


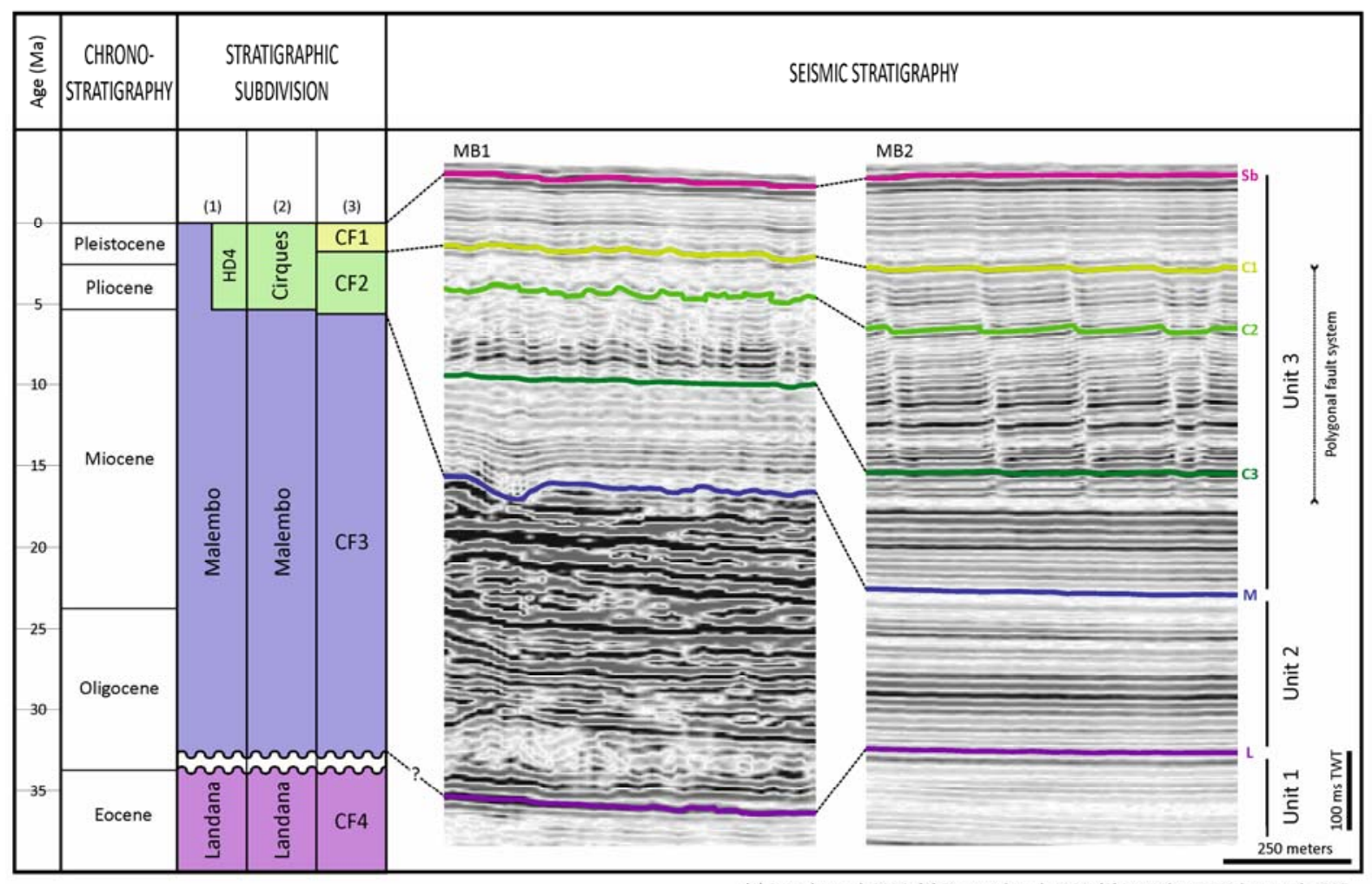

(1) Broucke et al. 2004; (2) Burwood et al. 1990; (3) Uenzelmann-Neben et al. 1997.

Figure 3. Seismic stratigraphy of mini-basin 1(MB1) and 2 (MB2). Sb = seabed (top of Unit 3); $\mathbf{C 1}=$ top of polygonal fault tier; $\mathbf{C 2}=$ reflector at middle of polygonal fault tier; $\mathbf{C} 3=$ base of polygonal fault tier; $\mathbf{M}=$ top of Unit 2; $\mathbf{L}=$ top of Unit 1. 


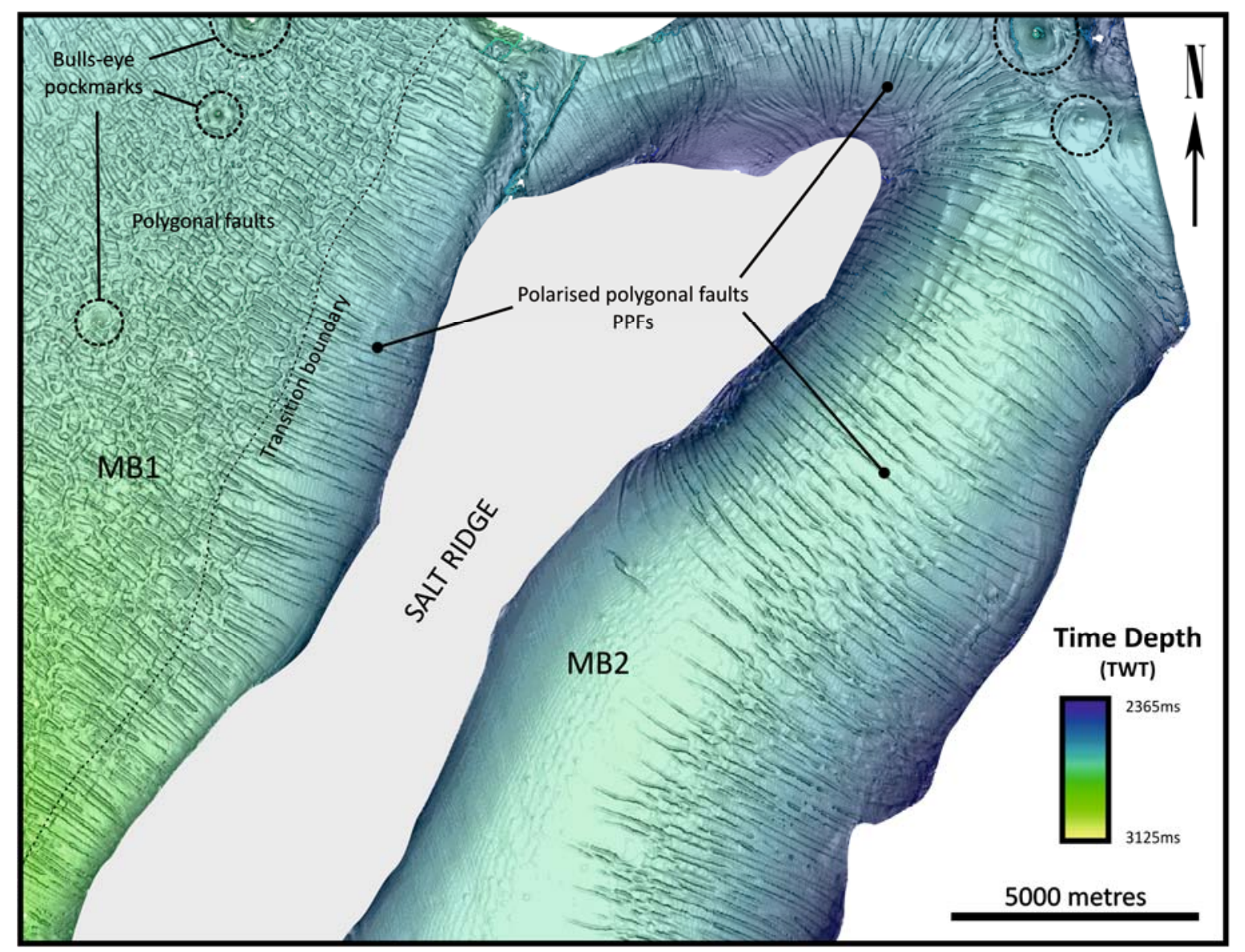

Figure 4. Structure and dip map of seismic horizon C2. Note the contrast between polygonal fault arrangements in different areas - the central region of mini-basin 1 exhibits a typical polygonal pattern, whereas mini-basin 2 and salt margins of mini-basin 1 present hybrid faults striking perpendicular to salt structures. Although minibasin 1 is pervasively affected by polygonal faulting, there are regions of mini-basin 2 absent of seismically resoluble discontinuities (ex., the south-western rim of mini-basin 2 depicted here). 
(A)

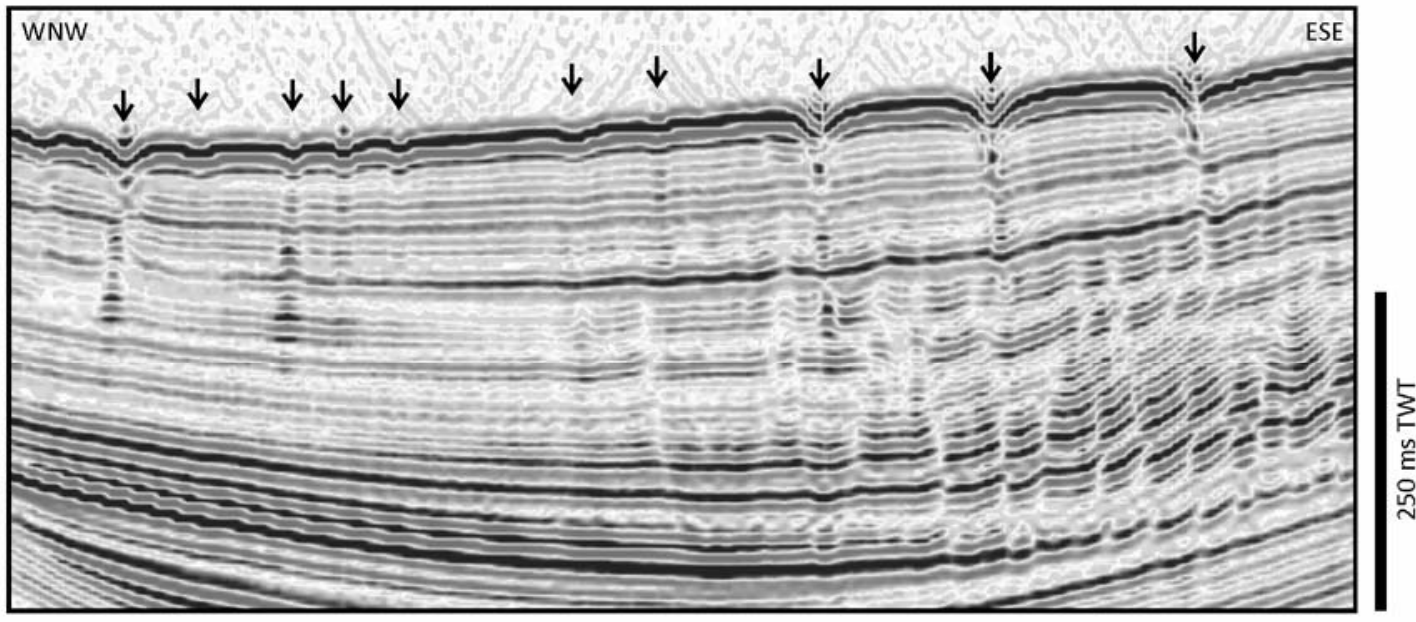

(B)
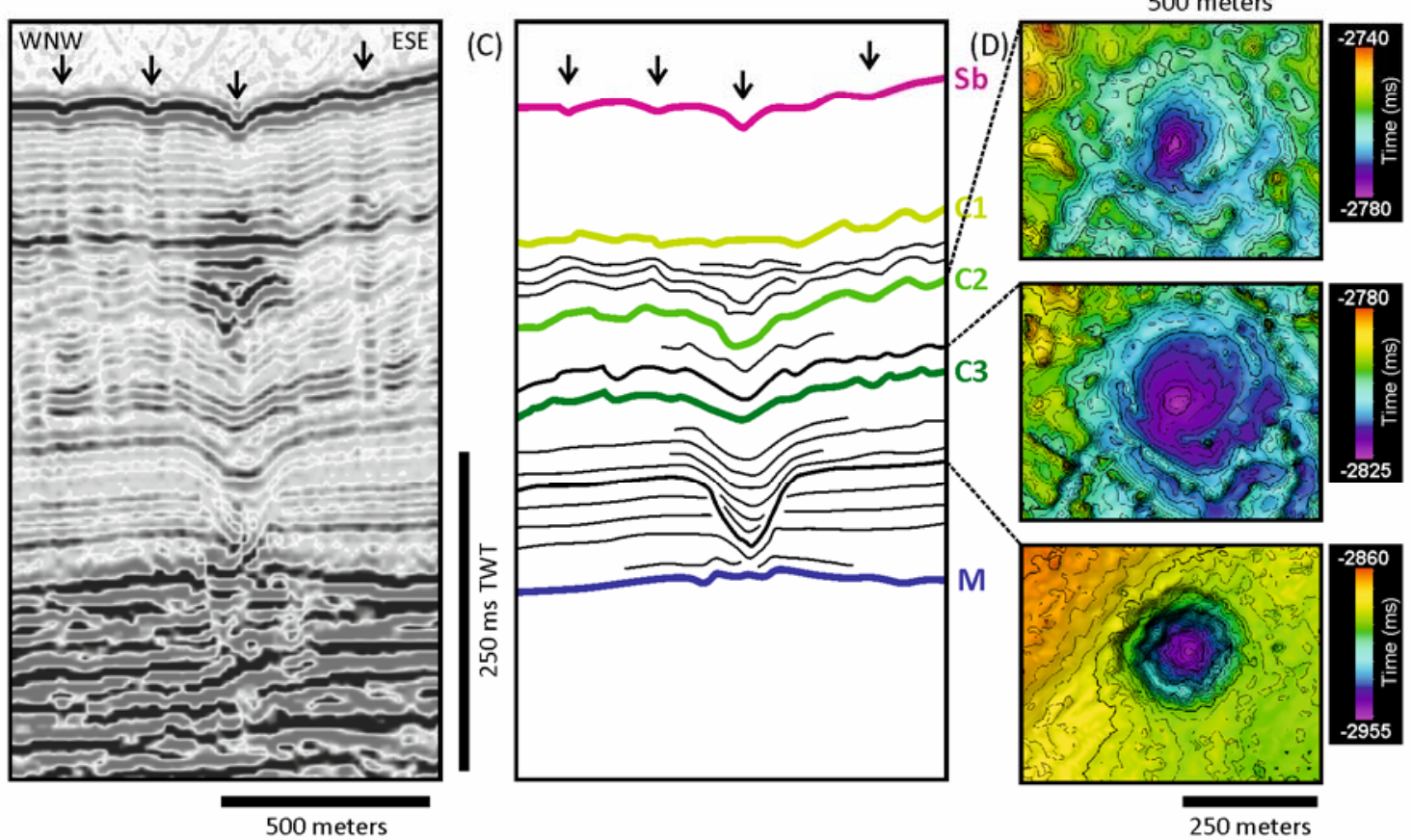

Figure 5. Seabed pockmarks versus subsurface bulls-eye pockmarks - seismic profiles and maps at event reflectors. A) Seismic section across mini-basin 2, showing seabed pockmarks, feeding pipes and the polygonal fault system within Unit 3. Arrows point to seabed pockmarks. Location of seismic section is in Fig. 2A. B) Seismic section intersecting a subsurface bulls-eye pockmark and several seabed pockmarks (black arrows) in mini-basin 1. C) Interpretation of seismic section shown in B). D) Maps of reflectors within the bulls-eye pockmark, showing its internal structure and variation with depth. 

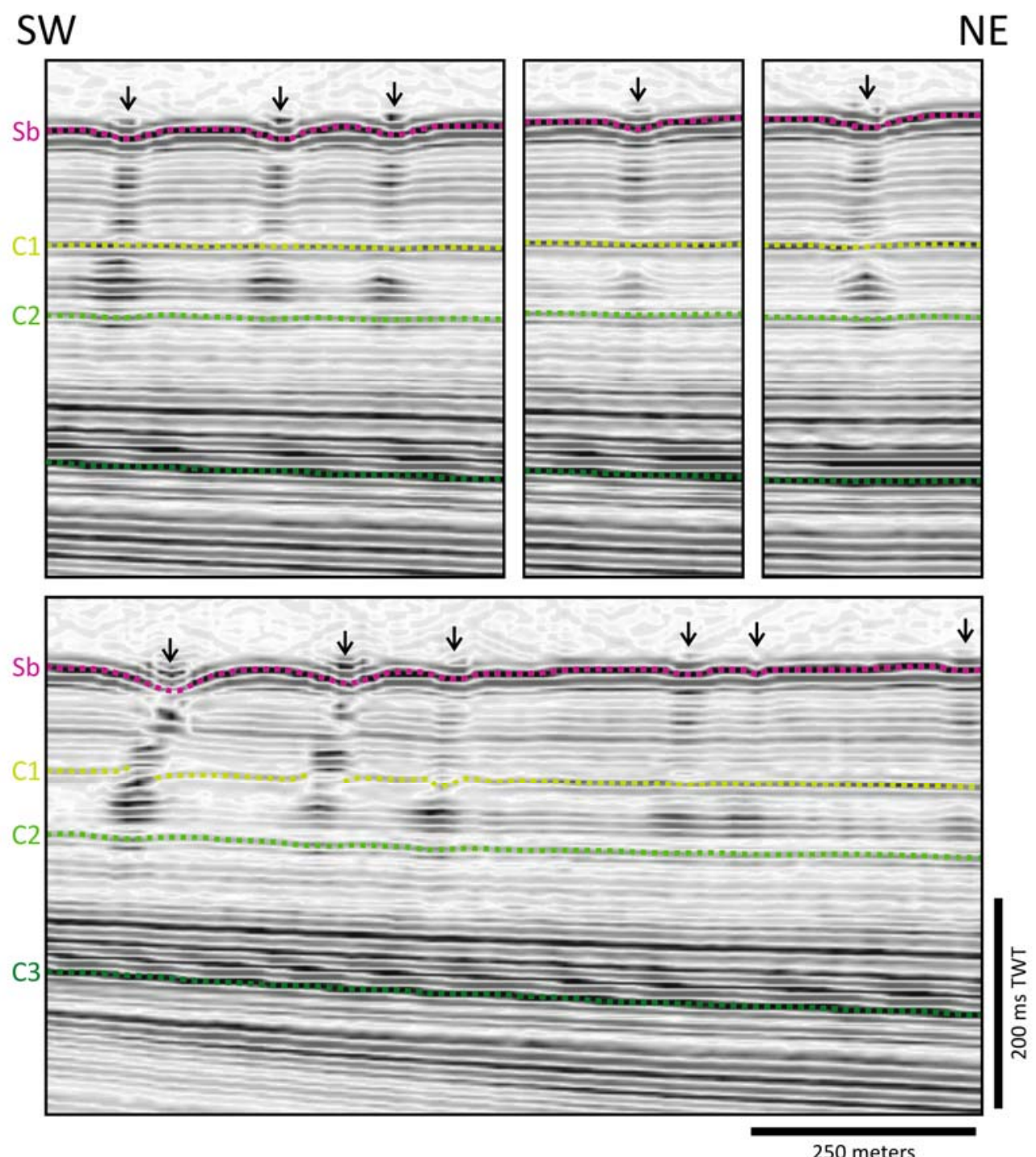

Figure 6. Seismic profiles of pipes present in non-polygonaly faulted area of mini-basin 2, occurring without being associated to any seismically resoluble discontinuity. Pipe defined as columnar zone of enhanced amplitude (vertically stacked amplitude anomalies), occasionally presenting disrupted internal reflectors. 

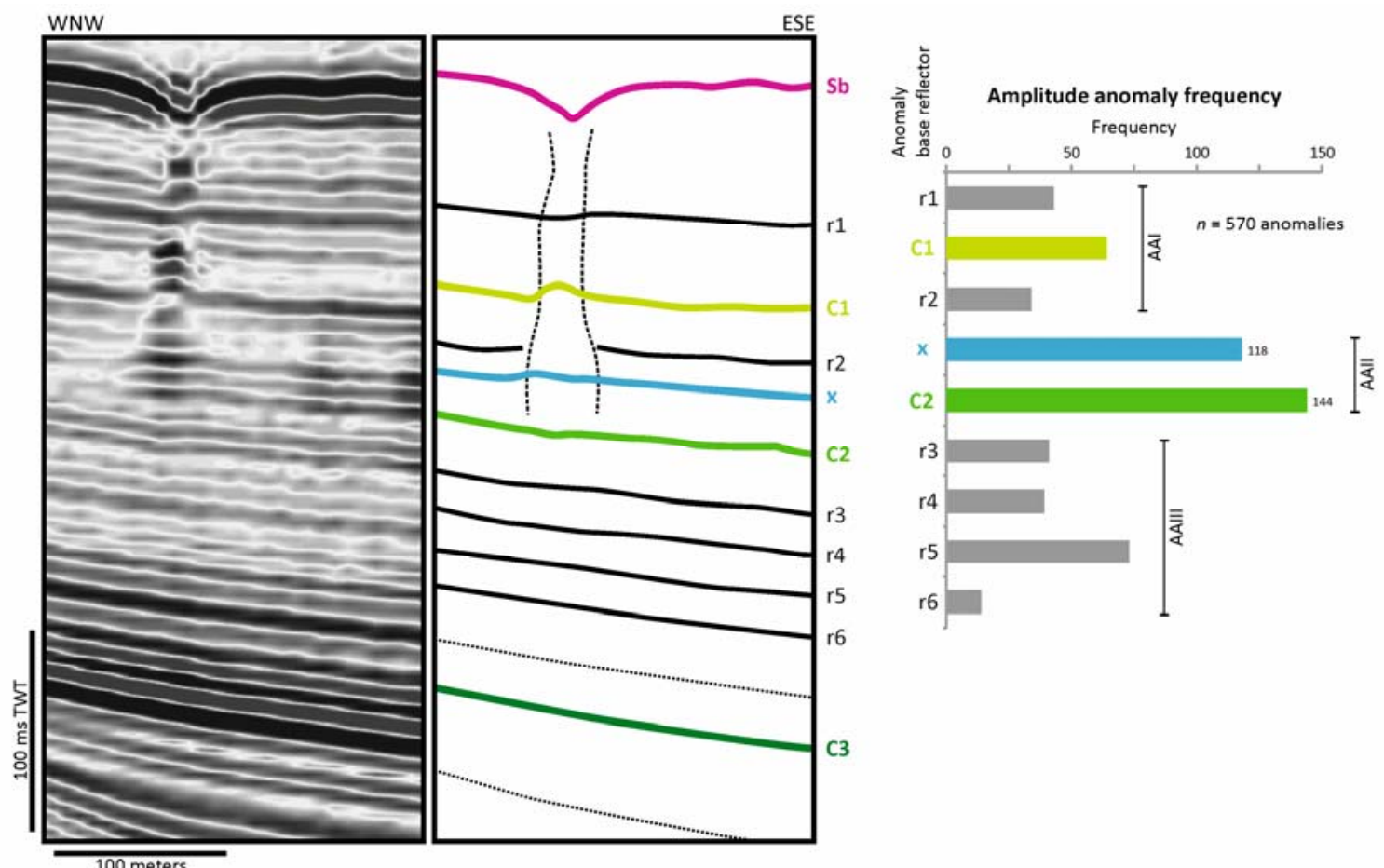

Figure 7. Pipe amplitude anomaly base reflector frequency. Each reflector in mini-basin 2 was consecutively numbered from seabed. The frequency histogram displays the number of pipes that rise from a particular reflector (pipe amplitude anomaly base). Most pipe bases are located between horizons $\mathbf{x}$ and $\mathbf{C 2}$ (46\% pipes). Data collected for 570 pipes in mini-basin 2. Pipe shown in seismic section is located in the non-polygonaly faulted area of mini-basin 2, and rises from reflector $\mathbf{C 2}$.

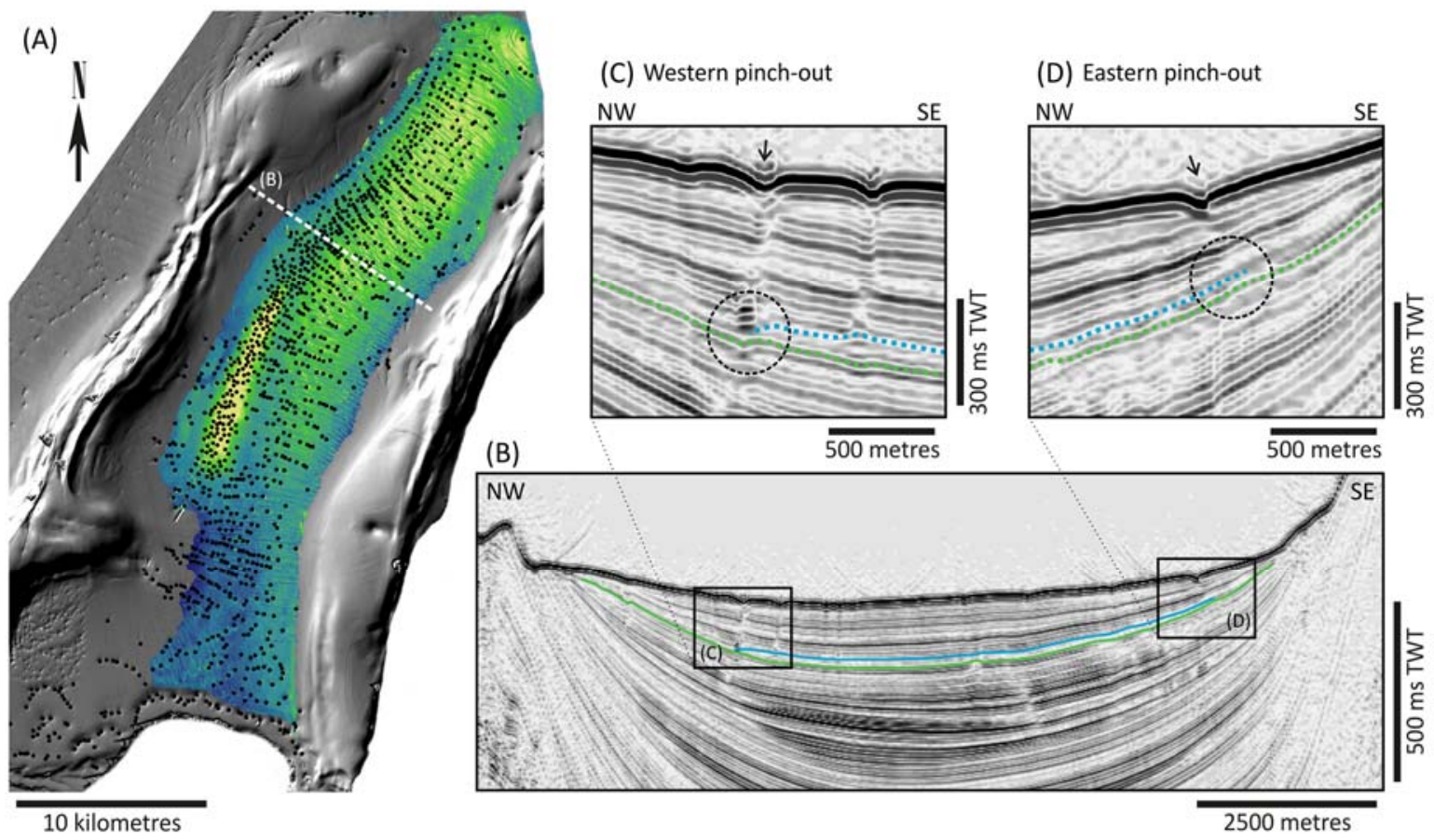

Figure 8. A) RMS amplitude map of the seismic interval between reflectors $\mathbf{x}-\mathbf{C 2}$, and seabed pockmark distribution - pockmarks within mini-basin 2 do not occur in areas where the interval was not deposited. Longest pockmark alignment parallel to the salt ridge is vertically above the pinch-out of the same interval. B) Transverse seismic section of mini-basin 2, highlighting interval x-C2. C) Close-up of pinch-out areas of $\mathbf{x}-\mathbf{C 2}$, showing internal reflections and pockmark vertically above pinch-outs (turbiditic levees/confined drifts?). 


\begin{tabular}{|c|c|c|c|c|c|c|c|}
\hline Reflector & AA freq. & \multicolumn{2}{|c|}{$\%$} & \multicolumn{2}{|r|}{ ANN } & \multicolumn{2}{|r|}{ ANN } \\
\hline r1 & 43 & 7.5 & & CLUSTERED & $R n=0.73 ; z=-3.33$ & & \\
\hline C1 & 64 & 11.2 & 24.7 & CLUSTERED & $\mathrm{Rn}=0.81 ; z=-2.84$ & CLUSTERED & $\mathrm{Rn}=0.79 ; z=-4.86$ \\
\hline r2 & 34 & 6.0 & & RANDOM & $\mathrm{Rn}=0.91 ; z=-0.978$ & & \\
\hline $\mathbf{x}$ & 118 & 20.7 & 460 & CLUSTERED & $R n=0.83 ; z=-3.47$ & & \\
\hline C2 & 144 & 25.3 & & CLUSTERED & $R n=0.64 ; z=-8.32$ & CLUSIERED & $\mathrm{kn}=0.82 ; \mathrm{z}=-5.55$ \\
\hline $\mathrm{r} 3$ & 41 & 7.2 & & CLUSTERED & $\mathrm{Rn}=0.70 ; z=-3.71$ & & \\
\hline r4 & 39 & 6.8 & & RANDOM & $R n=0.98 ; z=-0.23$ & & $D n=070$. \\
\hline r5 & 73 & 12.8 & 29.3 & CLUSTERED & $\mathrm{Rn}=0.76 ; z=-3.84$ & CLUSIERED & $\mathrm{Rn}=0 . / 4 ; z=-6.31$ \\
\hline r6 & 14 & 2.5 & & DISPERSED & $\mathrm{Rn}=1.97 ; z=6.95$ & & \\
\hline Total & 570 & 100.0 & 100.0 & CLUSTERED & $\mathrm{Rn}=0.91 ; z=-4.00$ & CLUSTERED & $\mathrm{Rn}=0.91 ; z=-4.00$ \\
\hline
\end{tabular}

Table 1. Spatial distribution analysis of amplitude anomalies in MB2. Average nearest neighbour test results shown for $99 \%$ of statistical significance. $\mathrm{AA}=$ amplitude anomaly; $\mathrm{ANN}=$ average nearest neighbour (Rn); $\mathrm{z}=\mathrm{z}$ score. 


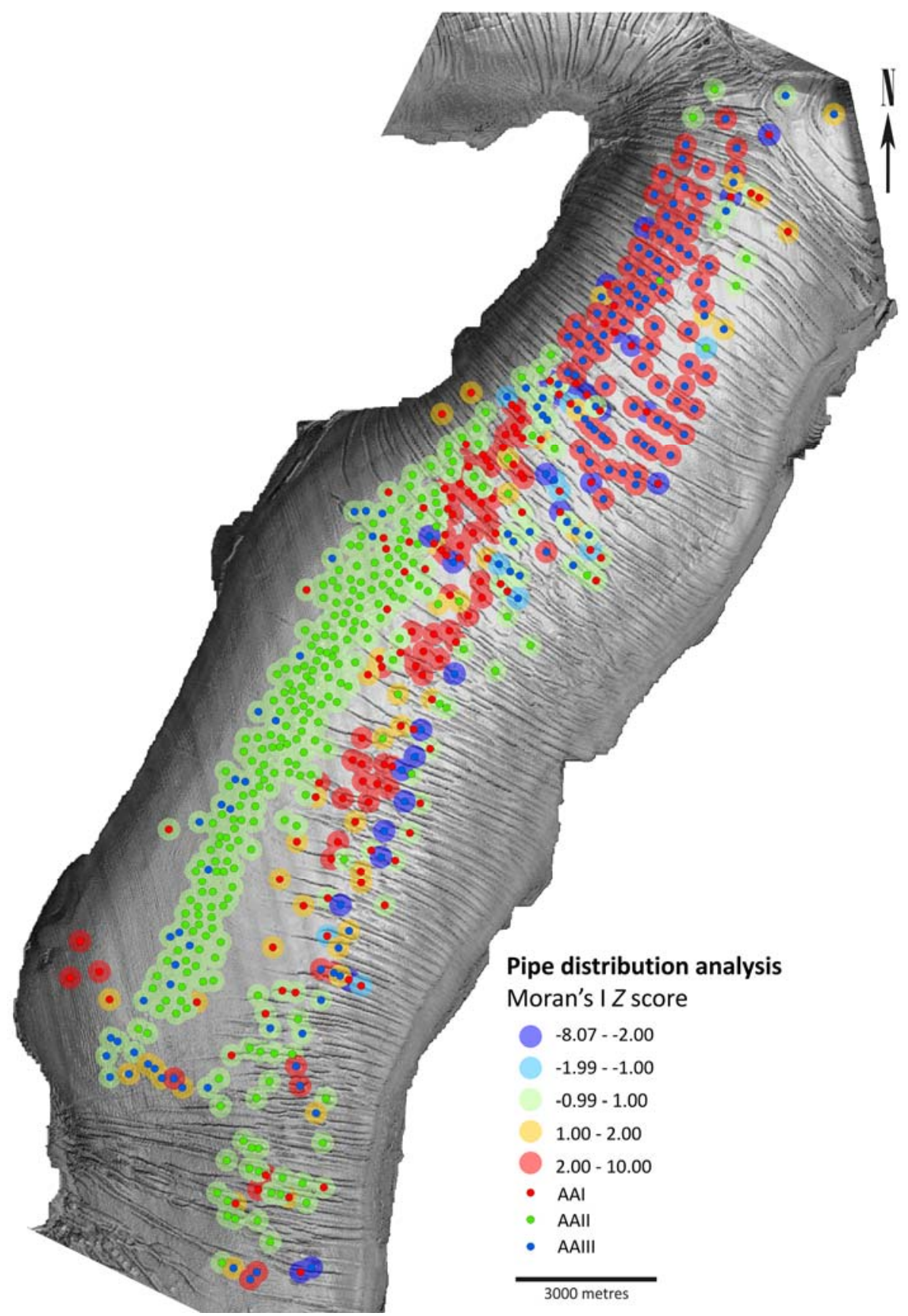

Figure 9. Spatial distribution of pipes within mini-basin 2, and their relation to underlying polarised polygonal faults. 
(Bi)

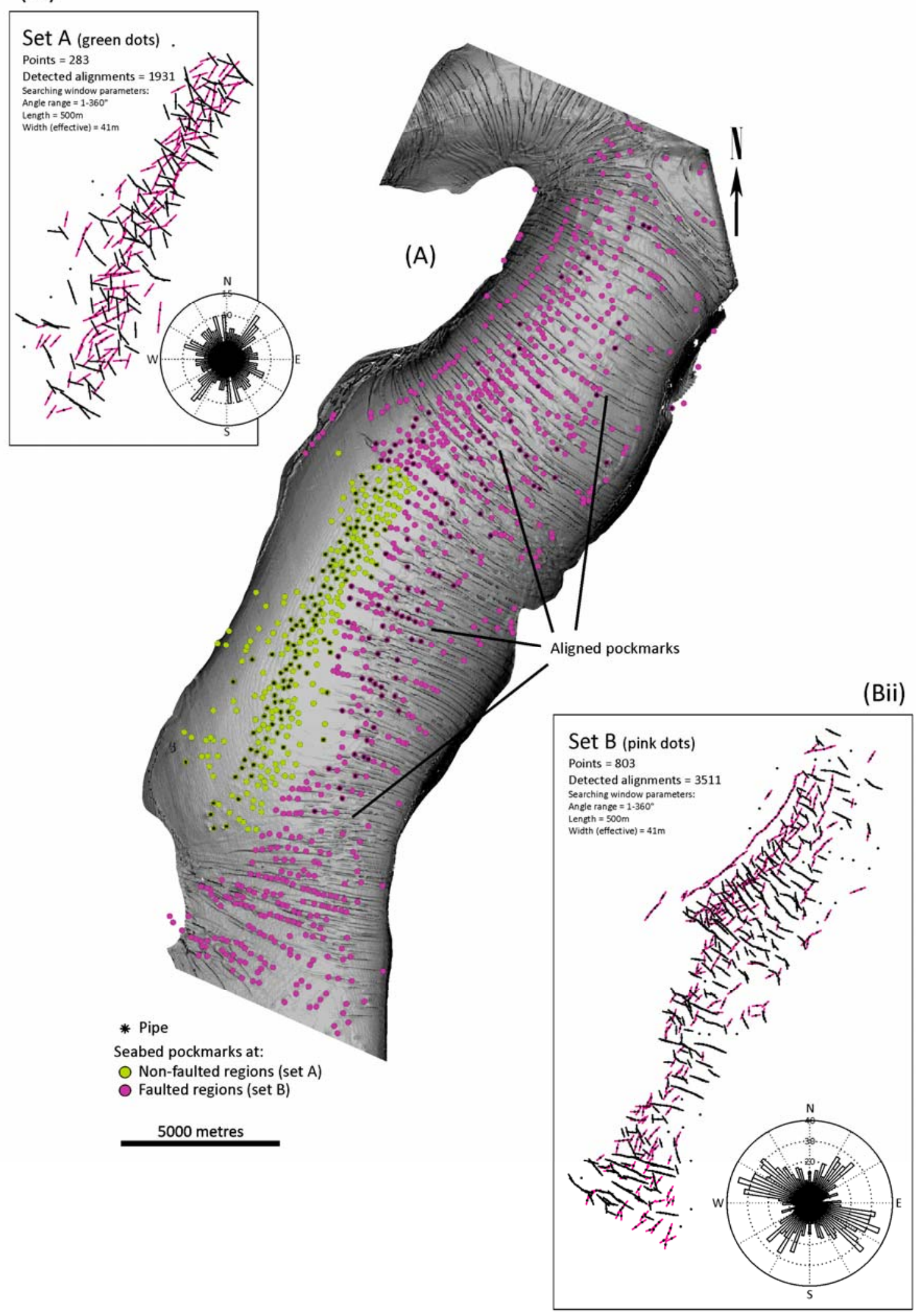

Figure 10. A) Spatial distribution of seabed pockmarks and pipes of mini-basin 2, and their relation to underlying hybrid polygonal faults. Two sets of pockmarks were defined: set A (green dots) - pockmarks not associated to any seismic resoluble discontinuity; set B (pink dots) - pockmarks occurring at faulted regions. Visually, set B pockmarks tend to be arranged in a linear fashion, striking parallel to underlying faults, whereas 
set A pockmark distribution appears to be more erratic. B) Seabed pockmark alignment detection. i) Alignment detection for set A. ii) Alignment for set B.

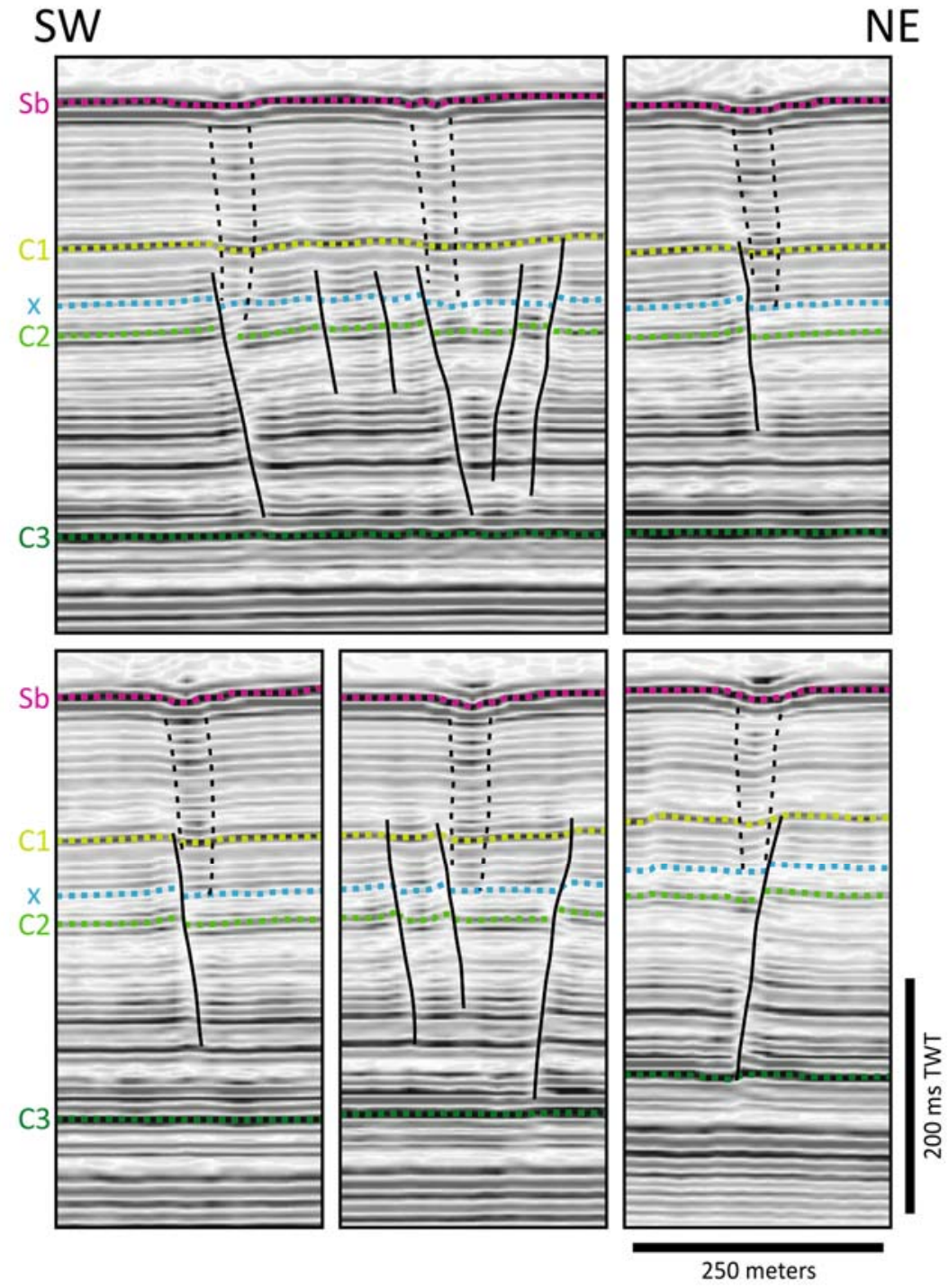

Figure 11. Seismic profiles showing pipe position in relation to polarised polygonal fault planes in mini-basin 2 - invariably, pipes occur on hanging wall blocks, rising from where faults intersect the interval between reflectors $\mathbf{x}$ and $\mathbf{C 2}$ (fluid source). 


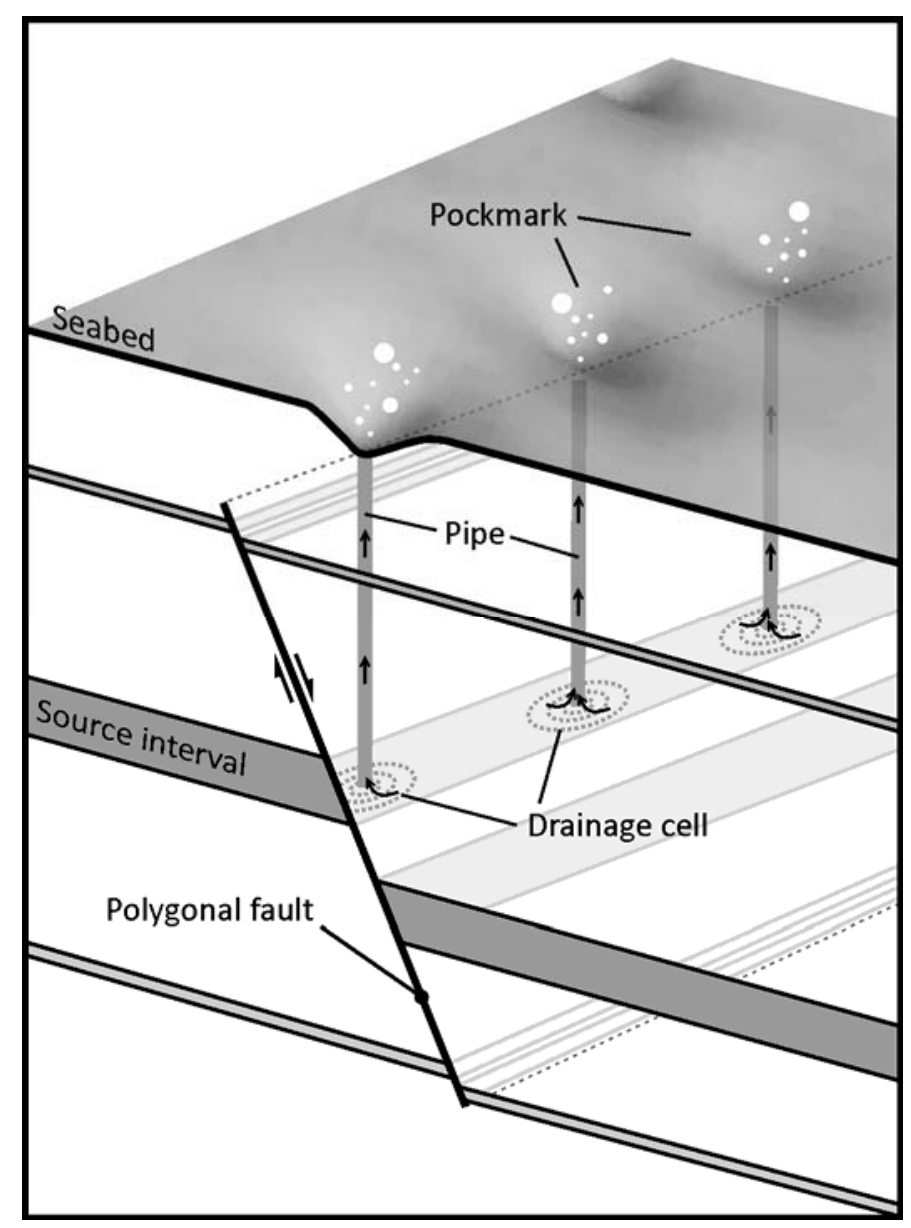

Figure 12. Fluid flow system - model schematics. 